\title{
Reforming retirement age in DB and DC pension systems in an aging OLG economy with heterogenous agents
}

\author{
Joanna Tyrowicz ${ }^{1,2^{*}}$, Krzysztof Makarski ${ }^{2,3}$ and Marcin Bielecki $i^{1,2}$
}

\author{
${ }^{*}$ Correspondence: \\ j.tyrowicz@uw.edu.p \\ 1 University of Warsaw, Warsaw \\ Poland \\ 2 National Bank of Poland, Warsaw \\ Poland \\ Full list of author information is \\ available at the end of the article
}

\begin{abstract}
We analyze the effects of increasing the retirement age in two economies with overlapping generations and within cohort ex ante heterogeneity. The first economy has a defined benefit system, and the second economy is in transition from a defined benefit to a defined contribution. We find that if increase in the retirement age is phased in a way that allows agents to adjust, welfare is not reduced and welfare effects have a similar magnitude and between-cohort distribution in both types of the pension systems.
\end{abstract}

Keywords: Retirement age, DB, DC, Pension system reform, Longevity

JEL codes: C60, C68, D63, E17, E21, H55

\section{Introduction}

In the policy debate on the consequences of longevity, the systemic reform of the pension system and the parametric reform are typically viewed as policy alternatives (see Auerbach et al. 1989; Boersch-Supan and Ludwig 2010; Fehr 2000; Hviding and Marette 1998). The former type of reform consists of switching from a defined benefit (DB) to a defined contribution (DC) scheme, whereas the latter comprises adjustments in minimum eligibility retirement age, contribution rates, or replacement rates. In countries with DC schemes, longevity implies substantial reduction of pension benefits. While this does not automatically require a policy response, in practice, it may translate to higher public expenditure as well, e.g., for instruments of poverty reduction among the elderly. In countries with a public DB scheme, longevity translates to higher public finance deficit. Given the substantive projected extension in the length of life, the foreseen increase in pension expenditure necessitates a policy adjustment.

Addressing the fiscal consequences of longevity, Heijdra and Romp (2009) emphasize that, generally, people tend to retire as early as legally allowed, despite rapidly increasing life duration (see also Sauré and Zoabi 2012). These empirical insights suggest that models with an exogenous retirement may fit well the data. Indeed, early exits despite longevity are inconsistent with perfect foresight rational agents, unless pension systems provide perverse incentives - a problem that may be addressed with exogenous retirement age. Giving a summary of multiple comparative cross-country studies, Gruber and

C 2016 Tyrowicz et al. Open Access This article is distributed under the terms of the Creative Commons Attribution 4.0 International License (http://creativecommons.org/licenses/by/4.0/), which permits unrestricted use, distribution, and reproduction in any medium, provided you give appropriate credit to the original author(s) and the source, provide a link to the Creative Commons license, and indicate if changes were made. 
Wise (2007) argue that retirement systems in most countries are not actuarially neutral. For example, Boersch-Supan (2000) provides an entire list of disincentives to extend the length of the labor market activity for Germany and some of the other European countries. Consequently, provided that leisure is a normal good, immediate retirement becomes a rational response to the incentives from the pension system, which apparently trumps other incentives, such as those stemming from longevity. ${ }^{1}$

The problem of pension system incentives to retire early is further attenuated by another type of concern: the heterogeneity of workers. While it is not customary to relax the assumption of one representative household within a cohort, few studies do that, e.g., Bucciol (2011); Cremer and Pestieau (2011); Fehr and Kindermann (2010); Fehr and Uhde (2014); Fehr et al. (2008); Hairault and Langot (2008); Hénin and Weitzenblum (2005); Kindermann and Krueger (2014); Kumru and Thanopoulos (2011); McGrattan and Prescott (2013); and St-Amant and Garon (2015). The consequences of within-cohort heterogeneity are shown to be substantial.

Summarizing, from a policy perspective, there seem to be three important gaps in the literature. First, is it possible to raise the retirement age in a way that would have universal welfare effects for all the cohorts? In other words, does this sort of parametric reform require redistribution between cohorts? Second, are these conclusions dependent upon the type of the pension system? In other words, does a systemic reform preclude the efficiency gains from a parametric reform? Third, to what extent are these results universal in a society where agents not only differ in birth cohort but are also heterogeneous within each cohort.

We contribute to the literature by addressing these three points with an overlapping generation model featuring ex ante heterogeneity within cohorts. We use the demographic projection of longevity to study the effects for consumption and wealth inequality. We construct two economies: (i) with a DB system and (ii) in a transition from a DB to a DC system. In these two economies, the baseline scenario keeps the effective retirement age constant, whereas the reform scenarios increases the retirement age-gradually or immediately. In this framework, we are able to analyze the aggregate and disaggregate welfare effects for each cohort-the former corresponding to a single representative agent within a cohort and the latter to possibly heterogeneous effects for agents of different abilities and preferences. In the simulations, retirement age path is set exogenously. Given the empirical evidence, this assumption is not controversial in the DB pension system. In the transition to the DC pension system, the link between contributions and pension benefits itself could imply incentives to remain active for a larger number of years. This implies that the welfare effects of increasing the retirement age in such a scenario represent an upper bound of the probable outcomes. ${ }^{2}$

To make our study of direct applicability, we calibrate the model carefully to the case of Poland-a country which introduced a change from a DB to a DC system, subsequently raised the de iure retirement age, and in the process of this transition will have experienced substantial extension in longevity. We find that whether or not the systemic reform is introduced, the welfare effects from increasing the minimum eligibility retirement age are of a similar magnitude. While they are welfare enhancing for all the cohorts, they also imply a downward intensive margin adjustment in the labor supply. Consequently, cohorts with less timespan to adjust to the reform may experience some negligible welfare deterioration. In fact, transition from DB to DC generates a substantial unexpected 
decrease in pension benefits for many cohorts. Our results hold irrespectively of preferences, i.e., welfare effects are of the same sign as the representative agent even for agents with a high preference for leisure and low patience. This makes the parametric reform of increasing the retirement age a natural complementarity in the transition phase, because higher pension benefits due to a longer working period and shorter collection period partially cushion the decrease in pensions due to the systemic reform. This is also the source of the welfare effects. Actually, if the retirement age reform is delayed, this effect disappears.

The paper is structured as follows. Section 2 gives an overview of the approaches followed in both strands of the literature to motivate our modeling choices. We present in detail the model in Section 3 and its calibration in Section 4. The results are discussed in two substantive parts: aggregate welfare and macroeconomic effects in Section 5 and detailed analysis of heterogeneous agents in Section 6. The paper is completed by the conclusions as well as the policy recommendations.

\section{Insights from the earlier studies}

In the literature that builds on the overlapping generation framework, it is customary to conceptualize the welfare implications of policy reform as a change in utility observed across cohorts between the baseline and the reform scenario, following among others Breyer (1989) and Feldstein (1995). Indeed, there has been an extensive body of literature applying this approach to analyzing the welfare implications of both pension systems and their reforms (see Fehr 2009; Lindbeck and Persson 2003 for an overview). The literature devoted to the topic of retirement age can be broadly divided into two types of approaches: the concept of an optimal retirement age and a welfare analysis for variety of the pension system reforms. The former of the strands gives the agents the ability to select the actual length of labor market activity in addition to the labor supply within each of the years of the activity, e.g., Cremer and Pestieau (2003) and Fehr et al. (2003). In some of the models, there are also political economy considerations, with voting over the socially optimal retirement age (see Fehr et al. 2012; Fenge and Pestieau 2005; Galasso 2008; Heijdra and Romp 2009).

Our paper fits closer to the second strand of the literature. One of the earliest articles on the topic-by Auerbach et al. (1989) - assumes that the size of the pension system remains constant, so with delayed retirement, contribution rates are reduced. In this setting, although the reform is, in general, welfare enhancing, the cohorts just prior to the retirement at the moment of introduction have insufficient room to adjust their labor supply during the lifetime, whereas the gains from reduced contribution rates are still small and over a short period of time. Thus, the reform as proposed by Auerbach et al. (1989) yields welfare loss for these cohorts. The subsequent studies in the field usually followed a different fiscal adjustment path. Typically, since the increase in the retirement age was among the considered pension reform scenarios, delaying labor market exit serves the purpose of reducing the fiscal pressure stemming from the pension system. The fiscal adjustments stemming from this include reduction in taxes or public debt.

Most of the results are optimistic in a sense that delaying retirement is a viable policy option for countries with growingly unsustainable pension systems. Fehr (2000) finds that increasing the retirement age for Germany would yield considerable improvement in fiscal stance. Díaz-Giménez and Díaz-Saavedra (2009) demonstrate that a feasible extension 
of the working duration in Spain would be able to put the pension system in balance even with further longevity (see also Jimeno et al. 2008). However, the welfare of the few initial cohorts would suffer as a result of the increase. In a comparative study for Germany, France, and Italy, Boersch-Supan and Ludwig (2010) find positive effects of increased labor supply and show compelling evidence that increasing the retirement age may be an effective way to achieve that goal. These papers consistently find welfare improvement with delaying the labor market exits of older cohorts, but sometimes, the gains are not universal and depend on the type of adjustment in the taxes and pension systems. Boersch-Supan et al. (2007) provide simulations of old-age labor supply responses to some policy changes, showing that, for example, actuarially neutral adjustments would increase the average endogenous exit age in Germany by more than 3 years. However, if the actuarially neutral system is exposed to other systemic risks, as is often the case with pre-funded schemes, increase necessitated by risk sharing cannot be offset by the increase in the retirement age (see Beetsma and Bucciol 2011).

As to the macroeconomic effects, except for improving the fiscal balance, there are obvious adjustments in the labor supply and capital. The reduction in the $K / L$ ratio stems from two effects. First, agents expecting lower taxes and/or higher pensions accumulate less wealth to finance old-age consumption (see Futagami and Nakajima 2001). Second, an increased $L$ mechanically results in a transitory reduction in $K / L$. In fact, during the period of the adjustment, economic growth slows down due to slower capital accumulation. Improved fiscal stance allows for reduction in taxes relative to the baseline scenario (even if time-wise they need to increase), which gives space to smoothing of the consumption paths and partly offsets welfare reduction due to less leisure.

The remarkable consistency of these results may stem from a single property: with increasing longevity, certain increase in the retirement age could be seen as a way to accommodate for longer expected life duration, thus keeping the relative proportion of the split between working periods and leisure periods unaffected. With most standard preferences, this sort of "reform" should have little or no welfare effects if consumption levels are unaffected and the baseline scenario assumes no change in survival probabilities (see Fenge and Pestieau 2005). This last assumption, however, is not likely to give a relevant baseline because in most countries increasing longevity is a major feature of the demographic changes. As argued by Boersch-Supan (2013), under such circumstances, welfare depends on opportunities related to aging, i.e., the gain in valuable life years. In fact, early retirement (observed in the data as inconsistent with the observed longevity increase, but consistent with perverse incentives in the modern pension systems) suggests that raising the retirement age will be welfare enhancing because it expands the choice set for the agents. In other words, if the lifetime amount of work is already optimal, extending the retirement age will incite households to reduce the hours supplied over the necessarily longer period. Conversely, if it is suboptimal, expanding the choice set can only improve welfare (see Boersch-Supan et al. 2007; Boersch-Supan and Ludwig 2010).

As to heterogeneity, a number of studies on retirement age-e.g., Boersch-Supan (2013) and Fehr et al. (2012) - accommodate for ex post heterogeneity, because agents may experience uninsurable idiosyncratic income shocks. However, none of them explore the inequalities stemming from both aging and unequal income paths within cohort. This is in striking discrepancy with the empirical research which shows that income and consumption inequalities increase with age and that a big part of this divergence can be 
explained by the redistributive properties of the pension system (see Castaneda et al. 2003; Storesletten et al. 2004). Furthermore, there is compelling evidence that individuals adjust private voluntary savings in response to the expected future pension benefits, which inevitably translates to changes in the wealth inequality. Domeij and Klein (2002) show that the generosity of the Swedish pension system actually reduces to zero the private savings among a large fraction of the population, making wealth inequalities twice as high as income inequalities in this country. Indeed, Hairault and Langot (2008) show that low-productivity individuals have little room to adjust via savings to increases in tax rates, thus boosting wealth and welfare inequalities in an economy that undertakes a parametric reform of a pay-as-you-go (PAYG) system. A similar effect is confirmed by Song (2011). Finally, in an empirical study, Sauré and Zoabi (2012) argue that as much as $40 \%$ of cross-country variation in the retirement age may be explained by differences in the occupational composition. Some occupations may make it difficult or impossible to continue labor market activity beyond a certain age. This finding may also explain why in many countries workers retire at the eligibility age despite incentives in the pension system.

Summarizing, the earlier literature suggests that raising the exit age is only welfare enhancing if the de iure retirement age is too low and the pension system provides disincentives to prolonging labor market activity beyond the official legal limit. If increased retirement age yields an actuarially neutral adjustment in pension benefits, welfare gains are more equally spread across cohorts. There is also evidence that increasing the retirement age may be more effective in easing the fiscal tension. Some studies argue that such policy generates greater welfare gain than reducing the pension benefits or increasing the contribution rates. These insights, however, mainly concern analyses within one pension system, most frequently the pay-as-you-go DB systems. Little is known about the differences in the welfare effects of increasing the retirement age under the DC pension system, ceteris paribus. There is no explicit analysis comparing the effects of delaying the retirement with and without a systemic pension system reform.

Our paper contributes to the literature by filling this gap. There are three main contributions. First, we tackle directly the issue of "time to adjust," by comparing three types of the reform: an immediate and gradual increase in the retirement age, a delayed and gradual increase, and, finally, a delayed rapid increase. Second, we analyze if these effects depend on whether or not an economy has already implemented a systemic change from a DB to a DC system. In order to be able to address these two points, we develop an overlapping generation model with population longevity. We have two types of economies: one with a DB system and one in a transition from a DB to a DC system. Third, we analyze these effects for ex ante heterogeneous agents, i.e., we explicitly ask what is the within-cohort distribution of the welfare effects. This last contribution seems particularly relevant from a policy perspective.

\section{Model}

We develop a general equilibrium overlapping generation model, with exogenous but time-varying growth as well as longevity. ${ }^{3}$ Economy is populated by $k=1,2, \ldots, K$ classes of agents with differentiated endowments and preferences (within one family of functions), who live for $j=1,2 \ldots, J$ periods facing a time- and age-specific mortality rate $\pi_{j, t}$. Agents have no bequest motive, but since survival rates until the age of $j$ at time $t-$ 
i.e., $\pi_{j, t}$ - are lower than one, in each period $t$, a certain fraction of subcohort $(j, k)$ leaves unintentional bequests, which are distributed within their subcohort.

\subsection{Production}

Individuals supply labor (time) to the firms. The amount of effective labor of age $j$ in subcohort $k$ used at time $t$ by a production firm is $L_{t}=\sum_{j=1}^{\bar{J}-1} \sum_{k=1}^{K} N_{j, k, t} \omega_{k} l_{j, k, t}$, where $N_{j, k, t}$ is the size of a $(j, k)$ subcohort at time $t$.

Perfectly competitive producers supply a composite final good with the Cobb-Douglas production function $Y_{t}=K_{t}^{\alpha}\left(z_{t} L_{t}\right)^{1-\alpha}$ that features a labor-augmenting exogenous technological progress denoted as $\gamma_{t}=z_{t+1} / z_{t}$. Standard maximization problem of the firm yields the return on capital $r_{t}=\alpha K_{t}^{\alpha-1}\left(z_{t} L_{t}\right)^{1-\alpha}-d$ and real wage $w_{t}=$ $(1-\alpha) K_{t}^{\alpha} z_{t}^{1-\alpha} L_{t}^{-\alpha}$, where $d$ denotes the depreciation rate on capital.

\subsection{Consumers}

Consumers are born at the age of 20 , which we denote $j=1$, at which time they are randomly assigned with individual productivity multiplier $\omega_{k}$ as well as utility function parameters. These values do not change until the agent dies and the model is fully deterministic. ${ }^{4}$ Thus, a subcohort $k$ of agents within its cohort is described uniquely by assigned values of $\phi, \omega$, and $\delta$ (see Section 4).

The year of birth determines fully the survival probabilities at each age $j$. At all points in time, consumers who survive until the age of $J=80$ die with certitude. The share of the population surviving until older age is increasing, to reflect changes in longevity. The data for mortality come from a demographic projection until 2060 and are subsequently treated as stationary until the final steady state (see Section 4). This modeling choice is conservative in the sense that DB systems are more fiscally viable if the population stabilizes.

At each point in time $t$, an individual of age $j$ and subcohort $k$ born at time $t-j+1$ consumes a non-negative quantity of a composite good $c_{j, k, t}$ and allocates $l_{j, k, t}$ time to work (total time endowment is normalized to one). In each period $t$, agents at the age of $j=\bar{J}_{t}$ retire exogenously. ${ }^{5}$ Consumers can accumulate voluntary savings $s_{j, k, t}$ that earn the interest rate $r_{t}$. Consequently, consumers' lifetime utility is as follows:

$$
U_{j, k, t}=u_{k}\left(c_{j, k, t}, l_{j, k, t}\right)+\sum_{s=1}^{J-j} \delta_{k}^{s} \frac{\pi_{j+s, t+s}}{\pi_{j, t}} u_{k}\left(c_{j+s, k, t+s}, l_{j+s, k, t+s}\right)
$$

where discounting takes into account time preference $\delta_{k}$ and the probability of survival. The instantaneous utility function is given by:

$$
u_{k}\left(c_{j, k, t}, l_{j, k, t}\right)=c_{j, k, t}^{\phi_{k}}\left(1-l_{j, k, t}\right)^{1-\phi_{k}}
$$

and $l_{j, k, t}=0$ for $j \geq \bar{J}_{t}$. In this specification, $\phi_{k}$ determines steady state labor supply. Labor income tax $\tau^{l}$ and social security contributions $\tau$ are deducted from gross earned labor income to yield disposable labor income. Following the Polish legislation, we assume that the labor income tax $\tau^{l}$ is deducted from the gross pension benefit to yield the disposable pension benefit. Interest earned on savings $r$ are taxed with $\tau_{k}$. In addition, there is a consumption $\operatorname{tax} \tau^{c}$ as well as a lump-sum $\operatorname{tax} \Upsilon$ equal for all subcohorts, which we use to set the budget deficit in concordance with the data. Received bequests are denoted by beq. When working, the agents are constrained by earned disposable income, bequests, and 
savings from previous periods with net interest. When retired, the agents are constrained by disposable pension benefit, bequests, and savings from the previous period with net interest. Thus, an agent of type $k$ at age $j$ in period $t$ maximizes her lifetime utility function $U_{j, k, t}$ subject to the following sequence of budget constraints:

$$
\begin{aligned}
\left(1+\tau_{t}^{c}\right) c_{j, k, t}+s_{j, k, t}+\Upsilon_{t} & =\left(1+\left(1-\tau_{t}^{k}\right) r_{t}\right) s_{j-1, k, t-1} \leftarrow \text { capital income } \\
& +\left(1-\tau_{t}^{l}\right)(1-\tau) w_{t} \omega_{k} l_{j, k, t} \leftarrow \text { labor income } \\
& +\left(1-\tau_{t}^{l}\right) b_{j, k, t}+b e q_{j, k, t} . \leftarrow \text { pensions and bequests }
\end{aligned}
$$

The full solution to the consumer problem is presented in Appendix 1.

\subsection{Pension system}

There are two economies, each with a different pension system: an economy with a defined benefit system and an economy in transition from a defined benefit system to a defined contribution one. The social security contribution rates are identical in the two economies, but the tax implicit in the pension system is not due to different algorithms for computing the pension benefits at retirement. Once the pension benefits are computed for each subcohort, they are indexed with the same rate in both systems and for all subcohorts. Both our pension systems are of the pay-as-you-go nature, so for the sake of brevity, we omit this identification when referring to the pension system DB or DC. The algorithms for computing the pension benefits are described below.

Defined benefit There is an exogenous contribution rate $\tau$ and an exogenous replacement rate $\rho$ with $b_{\bar{J}_{t}, k, t}=\rho \cdot w_{t-1} \cdot \omega_{k} \cdot l_{\bar{J}_{t}-1, k, t-1}$ holding for all $j, k$. The benefits are indexed annually. ${ }^{6}$ The system collects contributions from the working and pays benefits to the retired:

$$
\sum_{j=\bar{J}_{t}}^{J} \sum_{k=1}^{K} N_{j, k, t} b_{j, k, t}=\tau \sum_{j=1}^{\bar{J}_{t}-1} \sum_{k=1}^{K} \omega_{k} w_{t} N_{j, k, t} l_{j, k, t}+\Xi_{t}
$$

where $\Xi_{t}$ is a subsidy/transfer from the government to balance the pension system.

Transition to defined contribution The DC pension system collects contributions and uses them to cover for contemporaneous benefits but pays out pensions computed on the basis of accumulated contributions, as given by equation:

$$
b_{\bar{J}_{t}, k, t}=\frac{\sum_{s=1}^{\bar{J}_{t}-1}\left[\Pi_{l=1}^{s}\left(1+r_{t-j+\imath-1}^{I}\right)\right] \tau_{t-j+s-1} \omega_{k} w_{t-j+s-1} l_{s, k, t-j+s-1}}{\sum_{s=0}^{J-\bar{J}_{t}} \frac{\pi_{\bar{J}_{t}+s, t+s}}{\pi_{\bar{J}_{t}, t}}}
$$

where $r_{t}^{I}$ is defined by the rate of the payroll growth. Analogously to the PAYG DB case, the benefits are subsequently indexed annually.

The initial steady state has a DB system. In period one, unexpectedly, an economy shifts gradually towards a DC system. The gradual transition means that for all cohorts living already before $t=1$, initial capital is computed and implied in the DC system but the pensions allocated according to the DB rules are honored without any adjustments. Furthermore, agents who were at the age of $j=30$ or older at $t=1$ also continue to receive DB pension benefits. ${ }^{7}$ The obligatory contribution rate $\tau$ is kept the same as in the initial steady state and DB system. 


\subsection{The government}

The government collects taxes $\left(\tau^{k}\right.$ on capital, $\tau^{l}$ on labor, and $\tau^{c}$ on consumption, as well as a lump-sum tax $\Upsilon$ ) and spends a fixed share of GDP on unproductive yet necessary consumption $G=g \cdot Y$. After calibrating $g$ in the initial steady state, we keep it stationary throughout the simulations (i.e., constant per effective unit of labor). The government balances the pension system. Given that the government is indebted, it naturally also services the debt outstanding.

$$
\begin{aligned}
& T_{t}=\sum_{j=1}^{J} \sum_{k=1}^{K} N_{j, k, t}\left[\tau_{t}^{l}\left((1-\tau) w_{t} \omega_{k} l_{j, k, t}+b_{j, k, t}\right)+\tau_{t}^{c} c_{j, k, t}+\tau_{t}^{k} r_{t} s_{j-1, k, t-1}+\Upsilon_{t}\right] \\
& T_{t}+\left(D_{t}-D_{t-1}\right)=G_{t}+\Xi_{t}+r_{t} D_{t-1}
\end{aligned}
$$

We set the initial steady state debt $D_{t}$ at $45 \%$ of GDP, which was the actual value of debt to GDP ratio in Poland in 1999. We calibrate $\Upsilon_{t}$ in the steady state to match the deficit and keep it stationary (i.e., constant per effective unit of labor) throughout the rest of the simulation.

The government debt and consumption tax adjust in response to the changes in fiscal pressure. First, as deficit in the pension system occurs, the public debt is increased. However, the public debt cannot be allowed to increase infinitely. Following the Maastricht Treaty criteria as well as the constitution of Poland, we set the threshold of growth at $60 \%$ of GDP. Once this threshold is hit, consumption tax adjusts. Once all the adjustment in population and retirement age are fully accommodated by the economy, gradually, over 80 years, the public debt level is reduced back to $45 \%$ of GDP, through the consumption tax. The final and the initial steady states have thus identical levels of public debt share in the GDP.

\subsection{Market clearing}

In the equilibrium, the goods market clearing condition is defined as

$$
\sum_{j=1}^{J} \sum_{k=1}^{K} N_{j, k, t} c_{j, k, t}+G_{t}+K_{t+1}=Y_{t}+(1-d) K_{t} .
$$

This equation is equivalent to stating that at each point in time the price for capital and labor would be set such that the demand for the goods from the consumers, the government, and the producers would be met. This necessitates clearing in the labor and capital markets. Thus, labor is supplied according to:

$$
L_{t}=\sum_{j=1}^{\bar{J}-1} \sum_{k=1}^{K} N_{j, k, t} \omega_{k} l_{j, k, t},
$$

and asset market clearing condition is given by

$$
D_{t+1}+K_{t+1}=\sum_{j=1}^{J} \sum_{k=1}^{K} N_{j, k, t} s_{j, k, t}
$$

where $s_{j, k, t}$ denotes private savings. We describe the model solving in Appendix 2.

\section{Calibration}

This section describes the calibration of all structural parameters in the model as well as the ex ante heterogeneity of preferences and endowments. We first discuss the set 
of exogenous assumptions that underlie the simulations, which in our setting consist of demographics and technological progress. Then, we move to the macroeconomic structural parameters, i.e., the calibration of the initial steady state. Given that the model has the ex ante heterogeneity, we keep this part of the model stylized, along the description in the previous section, as now the model is already highly computationally intensive. Finally, we discuss the calibration of heterogeneous endowments and preferences. The summary of the calibration is presented in Table 3 in the Appendix 3.

\subsection{Exogenous assumptions}

The exogenous assumptions are taken from the European Commission Aging Work Group (AWG) outputs. The path of the technological progress encompasses the conditional convergence of all Member States as of 2030, whereas the demographic projections are available annually and with reference to each annual age cohort until 2060.

Demographics We keep the size of each new arriving cohort constant, to isolate the change in the demographic structure solely due to increasing longevity. Thus, $\forall t$ the size of each cohort at the age of $j=1$ is constant. The mortality rate projection for Poland is then used to compute the size of these cohorts at consecutive ages, thus yielding survival probabilities $\pi_{j, t}$. The projection is available until 2060. We assume both birth rate and survival rate to be flat after that period, so our population stabilizes after 2140 .

Technological progress The model specifies labor augmenting technological progress, which we calibrate to the path provided by AWG. The overall assumption behind these forecasts is that countries with lower per capita income will continue to catch up but around 2030 all countries' exogenous productivity growth will be converging slowly towards the steady state value of $1.7 \%$ per annum.

\subsection{Macroeconomic parameters}

Depreciation and investment Depreciation rate $d$ is calibrated to match the investment rate in the economy given the discount factor $\delta$, i.e., approximately $24 \%{ }^{8}$

Taxes There are no tax redemptions on capital income tax, so de iure and de facto tax rates were set equal, which implies $\tau_{k}=19 \%$. Labor income tax $\left(\tau_{l}\right)$ was set at an effective $11 \%$, which matches the rate of labor income tax revenues in the aggregate employment fund. Consumption tax $\tau_{c}$ was set at $11 \%$, which matches the rate of revenues from this tax in aggregate consumption in 1999. This tax is allowed to increase in the baseline and reform scenarios if debt hits the threshold of $60 \%$ share in GDP.

Pension system The original replacement rate $\rho$ in the DB system was set to match the share of the pension benefits in GDP in 1999, i.e., $5 \%$. Subsequently, the social security contributions were set to reflect the size of deficit in the pension system (denoted in our model as $\Xi$ ), which amounted to $0.8 \%$ of GDP in 1999 . In the DB system, the $\rho$ parameter is held constant throughout the simulation. Also, in all scenarios and all systems, the contribution rate is held at the same level as the initial steady state. With the changing population structure and depending on the pension system, the deficit of the pension system $\Xi$ varies and so does the total sum of benefits to be paid each year.

For cohorts already working under the defined benefit system, there is no data on accrued savings that could be used to compute pension benefits under defined contribution. We use the records of the Social Insurance Fund to recover these implied savings, based on the released sample of $1 \%$ of the population. To assure comparability with the 
model, the initial capital is expressed in terms of average wage $(w)$. Hence, we mitigate any within-cohort heterogeneity there may have been in the data by imposing an equal starting point to all individuals within a cohort.

\subsection{Heterogeneity of endowments and preferences}

We have three dimensions of individual within-cohort heterogeneity: impatience and preference for leisure in the case of preferences and productivity factor in the case of endowments. Following the previous insights from Hénin and Weitzenblum (2005) and McGrattan and Prescott (2013) as well as Kindermann and Krueger (2014), we calibrate them using a micro dataset: the Structure of Earnings Survey. ${ }^{9}$ In our model, the productivity endowment is allocated once for the entire lifetime, which is in stark contrast to the literature with ex post heterogeneity due to income or labor supply shocks during the lifetime. This also implies that the age-productivity profile is flat in our setting. We consider this to be a conservative assumption, since we want to avoid the confounding between the changes in the exogenous productivity rate (identical in the reform and baseline scenarios) and the change in the structure of the working force (which occurs in the reform scenario only). Similarly, preference for leisure is set once for the whole lifetime. Thus, we cannot directly replicate the distribution of the working/non-working population (i.e., pick from data a share of individuals who do not currently participate in the labor market to proxy for a share of individuals who in the model never participate in the labor market).

Productivity endowment $\left(\omega_{k}\right)$ We estimate a standard Mincerian wage regression with age (linear and squared), education, occupation, industry, and region controls, as well as the form of contract (fixed term or indefinite duration) and form of employment (part-time, full-time, weekends, etc.). We use total hourly wage, including overtime and bonuses. We use fitted value of log earned hourly wage against the mean of this prediction for the individuals who were active in the labor market for up to 5 years after graduation. Thus, we obtain a distribution of productivity multipliers of $\omega$ (see Fig. 1a), i.e.,

$$
\omega_{k} \in\{0.6 \omega, 0.7 \omega, 0.8 \omega, 0.9 \omega, 0.95 \omega, 1.0 \omega, 1.05 \omega, 1.1 \omega, 1.15 \omega, 1.2 \omega\}^{10} .
$$

Note that heterogeneity in $\omega$ will work as a shift factor in our model, without effect on the slope. Thus, it is not likely to imply a high variation in terms of welfare.

Preference for leisure $\left(\phi_{k}\right)$ We first calibrate the macroeconomic employment rate, at $55.3 \%$ in 1999 , to match the data. This is consistent with the average number of hours
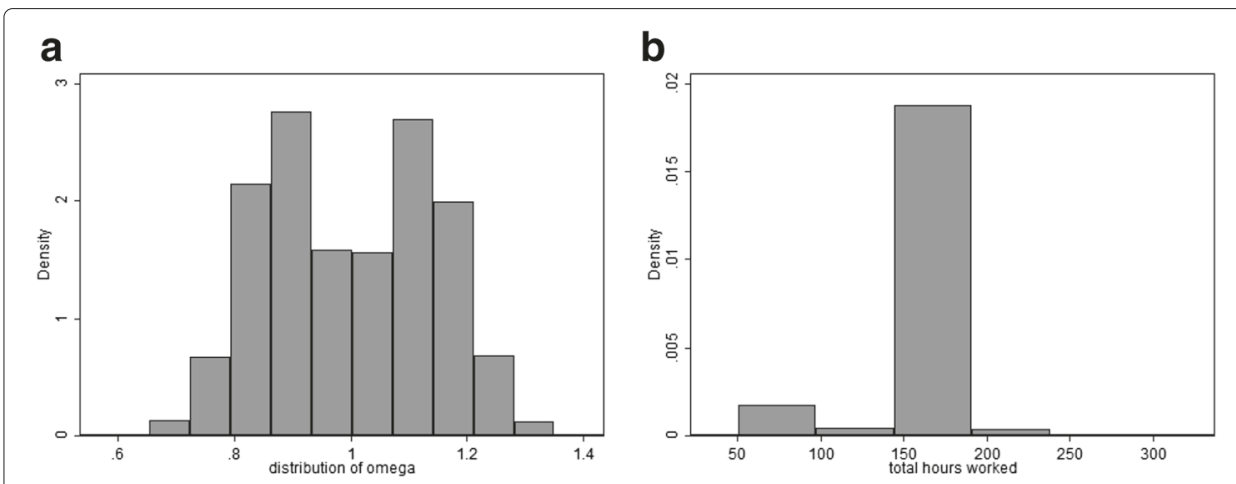

Fig. 1 Calibrations based on the Structure of Earnings Survey, 1998. a Calibration of productivity. b Calibration of preference for leisure 
worked-on average in this period 2050 annual hours according to the Conference Board Total Economy Database, i.e., $51.5 \%$ of the total workable time. We rely on reported hours actually worked (see Fig. 1b) in the Structure of Earnings Survey which ranges from 31 to $206 \%$ of the regular working time to obtain the individual multipliers of the preference for leisure $\phi$, i.e.,

$$
\phi_{k} \in\{0.5 \phi, 1.0 \phi, 1.5 \phi, 2.0 \phi\} .
$$

Discount factors $\left(\delta_{k}\right)$ The aggregate value $\delta$ was set to 0.99 to match the interest rate of $6.3 \%$, similar to Nishiyama and Smetters (2007) and consistent with the rate of return on the asset portfolio of roughly $7 \%$. There are no empirical counterparts for the individual $\delta_{k}$ for Poland. We thus chose the following multipliers for $\delta$

$$
\delta_{k} \in\langle 0.98 \delta, 1.0 \delta, 1.02 \delta\rangle,
$$

with the middle value pertinent to $40 \%$ of each cohort and the other two values split equally. While heterogeneous time preference is rather seldom in the literature, it replicates the approach of Hairault and Langot (2008) and McGrattan and Prescott (2013) who use heterogeneous morbidity rates. The demographic projection for Poland is only split by genders, so instead, we rely on $\delta_{k}$ (see also Doepke et al. 2015).

\subsection{The implied within-cohort heterogeneity}

The adopted small differences in the parameters of the utility function generate sufficient variation in the life cycle path of labor supply, consumption, and savings. In fact, the Gini coefficient for consumption in the initial steady state reaches approximately 25.5, which is a fair approximation of what is observed in the data (see Brzezinski 2011). ${ }^{11}$ In terms of individual-level differences, they are best observed in life cycle wealth profiles. Subcohorts with lower leisure preference (higher values of $\phi$ ) provide lower labor supply and have lower lifetime consumption path, ceteris paribus (see Fig. 2a-c). More patient subcohorts choose a consumption pattern with an inverse $U$ shape and declining labor supply over lifetime (see Fig. 2d-f). Finally, individual endowments work as shift parameters rather than slope parameters, i.e. they have little effect on labor supply, but magnifying productivity implies higher consumption (see Fig. $2 \mathrm{~g}-\mathrm{i}$ ). The negligible effect for the labor supply decision is associated with the fact that productivity endowment has the same value for the entire lifetime, i.e., has no consequences for the intra-temporal consumption-labor choice, nor inter-temporal labor choice (income and substitution effects have similar magnitudes and opposing signs).

\subsection{Simulation scenarios}

Agents supply no labor when they receive pension benefits, which occurs at the age of $\bar{J}$. They receive these benefits as of this age till death.

Such exogenous retirement age could imply inefficiency, especially in the DC system. Yet, it is an empirical regularity in most advanced economies that workers claim pension benefits as early as possible, usually also reducing-often to zero-labor supply (see Gruber and Wise 2007; Heijdra and Romp 2009). Unlike agents in macroeconomic models, workers tend to express the sense of being tired or unable to keep up with the expectations at older ages, even prior to reaching the minimum eligibility retirement age, as analyzed in the European context by Wahrendorf et al. $(2012,2006)$ and Van Solinge 

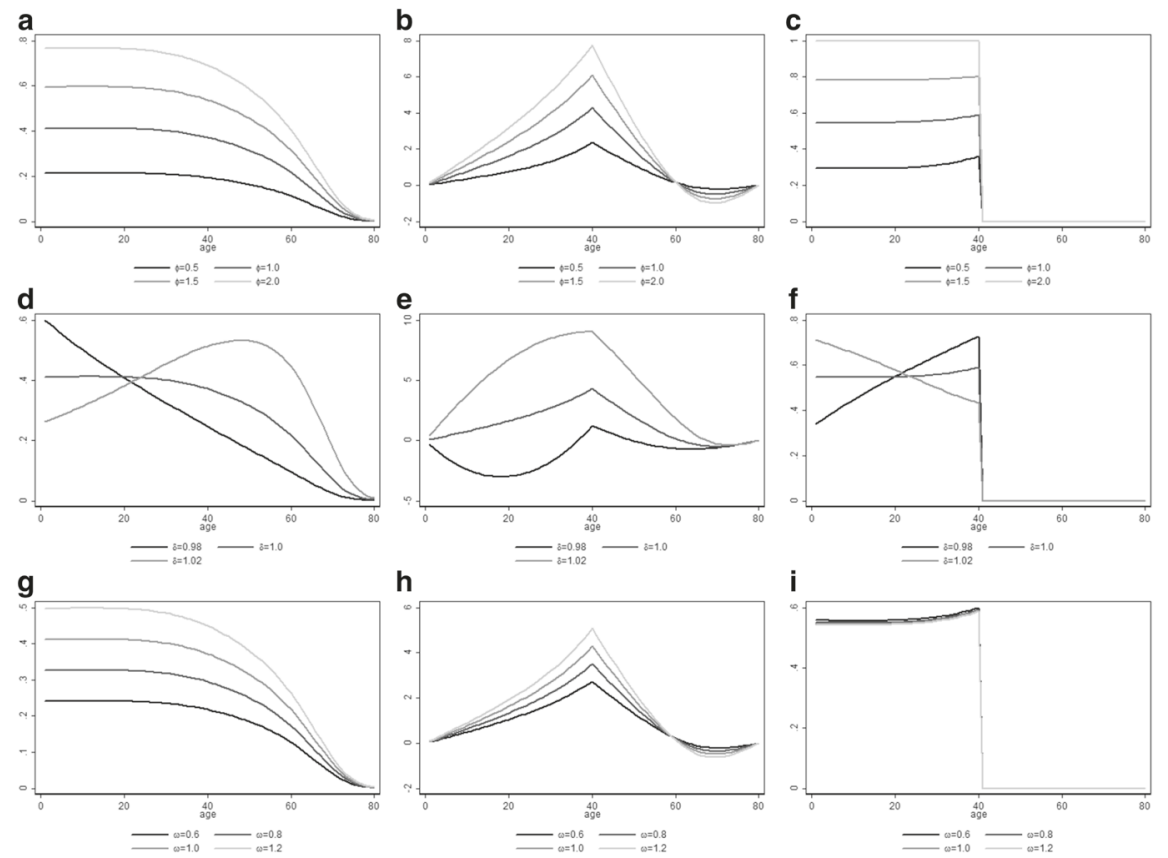

Fig. 2 Life cycle paths of consumption, savings, and labor supply -initial steady state. Note: For any given set of results, all multipliers but the analyzed one are set to 1 . In the simulations, the heterogeneity is allocated simultaneously along all three dimensions. Thus, subcohorts differ in both level and slope effects, depending on the combination of values $\phi, \delta$, and $\omega$. Varying leisure preference $\phi$ : a consumption, $\mathbf{b}$ savings, and $\mathbf{c}$ labor supply. Varying impatience $\delta$ : $\mathbf{d}$ consumption, e savings, and $\mathbf{f}$ labor supply. Varying endowment $\omega$ : $\mathbf{g}$ consumption, $\mathbf{h}$ savings, and $\mathbf{i}$ labor supply

and Henkens (2010) with the use of SHARE network data or by Vodopivec (2010) for Slovenia. In fact, following Siegrist et al. (2007) as well as Schnalzenberger et al. (2014), it seems that early retirement decisions are motivated by the same set of factors in terms of accumulated fatigue and perceived health status.

To replicate that feature in a general equilibrium setting with standard preferences, one could follow two paths. First, impose an exogenous retirement age, as is the case in this paper. This typically necessitates that such economy will be dynamically inefficient (if unconstrained, agents would have worked longer and saved less). The alternative solution is to impose an age-specific productivity pattern, as to reflect gradually decreasing returns to hours worked. Assuming a flat pattern of endowments, as already argued, we take a conservative assumption, i.e., changing labor composition due to a longer working period has no direct effect on the overall output per effective unit of labor. However, empirical evidence concerning the age-productivity patterns is ambiguous. Despite numerous studies, the shape of the age-productivity pattern remains a discretionary area, due to the confounding nature of the age, cohort, and year effects, with an additional bias coming from selection effects in both the youngest and oldest age groups. ${ }^{12}$ Most of the studies assume an inverted U-shaped pattern, but numerous empirical results show that after isolating the pure age effect on productivity, the profiles prove to be fairly flat and-if anything-slightly increasing until the age of 65 (see, e.g., Boersch-Supan and Weiss 2011; Deaton and Paxson 1998; Myck 2010). Assuming a lifetime age-productivity pattern, one 
would also have to consider varying leisure preference over lifetime, opening yet another channel of discretionary choices. ${ }^{13}$

In the baseline scenario, the retirement age is kept constant in spite of increasing longevity. We run the baseline simulation for both types of the pension system, i.e., for the DB and the transition to a DC system. We propose three reform scenarios:

(i) As of $t=11$, we gradually increase the retirement age at the rate of 1 year of additional work every decade until $\bar{J}=47$-we call this scenario immediate and gradual increase.

(ii) As of $t=41$, we gradually increase the retirement age at the same rate until $\bar{J}=47-$ we call this scenario gradual delayed increase.

(iii) As of $t=41$, we immediately set $\bar{J}=47$ - we call this scenario delayed immediate. ${ }^{14}$

All schedules of the retirement age are visible to agents as of $t=1$, i.e., these are not unexpected reforms. Admittedly, the reform introduced as of $t=11$ leaves agents less room to adjust the instantaneous labor supply.

The three types of the reforms permit to address different questions. First, by comparing the welfare effects of the immediate and the delayed increase in the retirement age, we are able to address the question of whether the "time to adjust" is an important channel of affecting welfare. Namely, as argued by Boersch-Supan and Ludwig (2010), some intensive margin adjustment in labor supply is to be expected, when the reform of the retirement age ushers the extensive margin adjustment. Second, by increasing the retirement age in an economy with a DB system and an economy in transition from a DB to a DC system, we can capture the interaction between systemic and parametric reforms in terms of welfare and fiscal effects. Third, by comparing gradual to rapid reforms-both expected by the consumers-we provide insights on the relative importance of the timing of the reform and its speed. This may be particularly important for the political economy of such reforms as well as public support.

In the case of both pension systems, the baseline scenario and the reform scenario alike are subjected to the longevity and exogenous productivity growth slowdown (see Section 4). These simulations yield income and consumption distributions across cohorts and within cohorts (across subcohorts) for each point in time. For each subcohort of type $k$, we may observe the change in welfare between the baseline scenario of flat retirement age and the reform scenario of increasing the retirement age. Since these are computed at equilibrium, agents fully internalize the changes in prices and pension benefits as well as fiscal closure (the consumption tax).

\section{Aggregate welfare effects}

The aggregate welfare effects of the reform are fairly similar for a DB system and for a transition to a DC system; for all of the analyzed reform scenarios, see Table 1. In addition to the overall welfare, we report the number of cohorts who observe a welfare loss as well as the average loss observed by these cohorts. The welfare gain amounts to roughly 3.3$6.0 \%$. Higher welfare gains under transition to DC than under the DB system suggest a positive reinforcement between the systemic and retirement age reform. The extent of the welfare gains is slightly higher than the effects of a systemic reform, as reported for a similar calibration and economy in Makarski et al. (2016). ${ }^{15}$ 
Table 1 Net consumption equivalent from extending the retirement age

\begin{tabular}{|c|c|c|c|c|c|c|}
\hline \multirow[b]{2}{*}{ Reform scenario } & \multicolumn{2}{|c|}{ Overall welfare } & \multicolumn{2}{|c|}{ \# of losing cohorts } & \multicolumn{2}{|c|}{ Maximum loss } \\
\hline & $\mathrm{DB}(\%)$ & Trans. to DC (\%) & $\mathrm{DB}$ & Trans. to DC & $\mathrm{DB}(\%)$ & Trans. to DC (\%) \\
\hline Gradual and immediate increase & 4.60 & 5.97 & 30 & 36 & -0.38 & -0.52 \\
\hline Gradual delayed increase & 3.29 & 4.60 & 24 & 28 & -0.03 & -0.07 \\
\hline Rapid delayed increase & 4.61 & 5.44 & 28 & 22 & -0.14 & -0.12 \\
\hline
\end{tabular}

Aggregate welfare effect reported and unweighted sum of cohort welfare effects for the cohorts affected by the reform. Average loss computed only among the losing cohorts

Clearly, the channels through which gains materialize differ between the DB system and the transition to a DC system (see Fig. 3). Large effects from postponing the retirement age are especially apparent when comparing the tax rates between the pension schemes. In fact, the implied tax rate in DB without an increase in retirement age goes up by $60 \%$, which explains why the welfare gains from delaying retirement are so large. Since the DC system is inherently balanced, the adjustments here are much lower (up to $20 \%$ ). Accordingly, in the DC system, the largest part of the welfare gain comes from substantially increased pension benefits. While they remain essentially unchanged under $\mathrm{DB}$, in the transition to DC, they increase by as much as $10-12 \%$.

Raising the retirement age is of crucial importance for determining the balance of the pension system under the DB scheme. A higher contribution base and lower payments imply lower deficit, which is clearly visible in Fig. 4a, b. In the transition to DC, the effects of raising the retirement age are of only transitory nature and follow from changes in the contemporaneous balance between contributions and payments (due to the abrupt

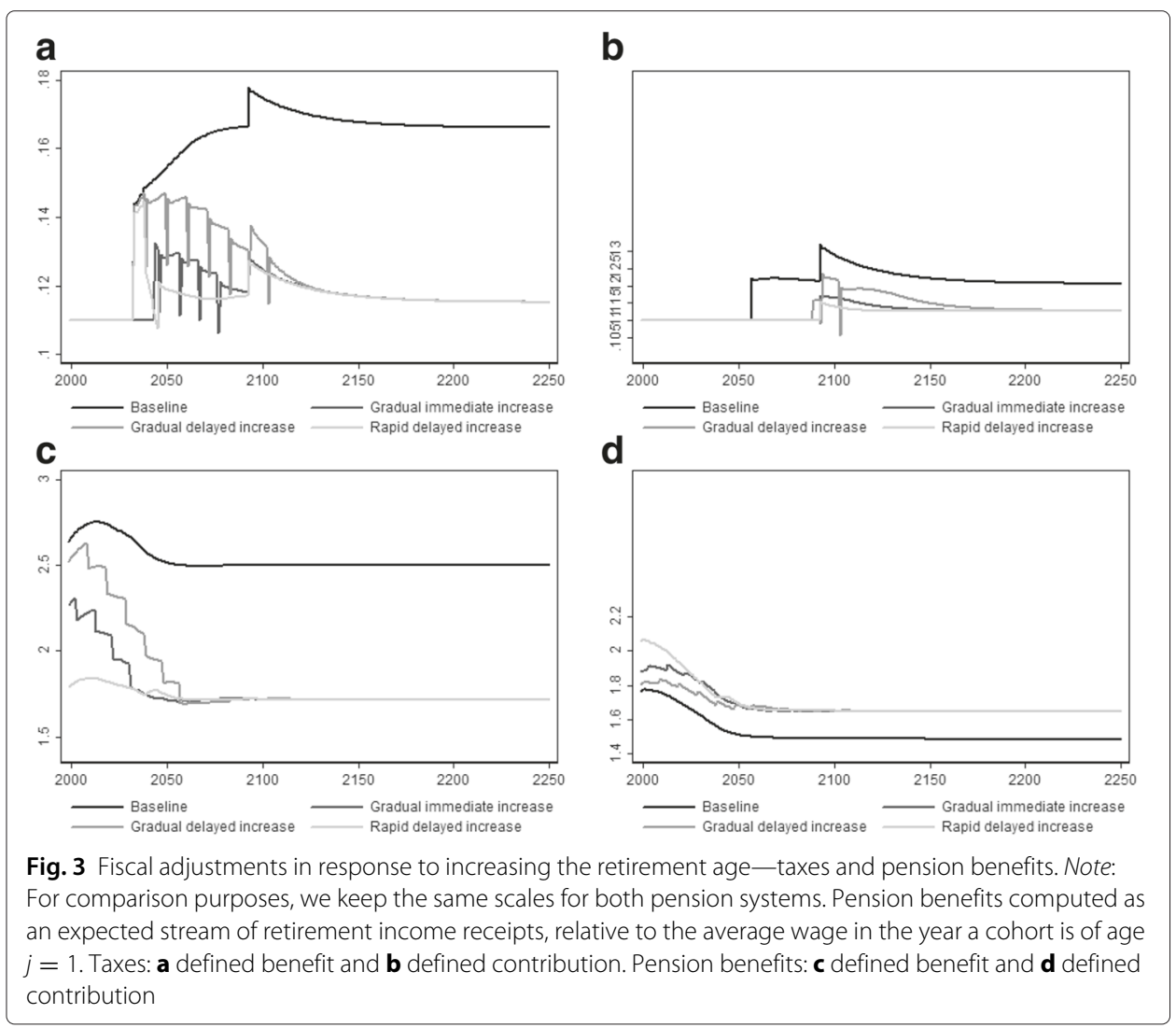




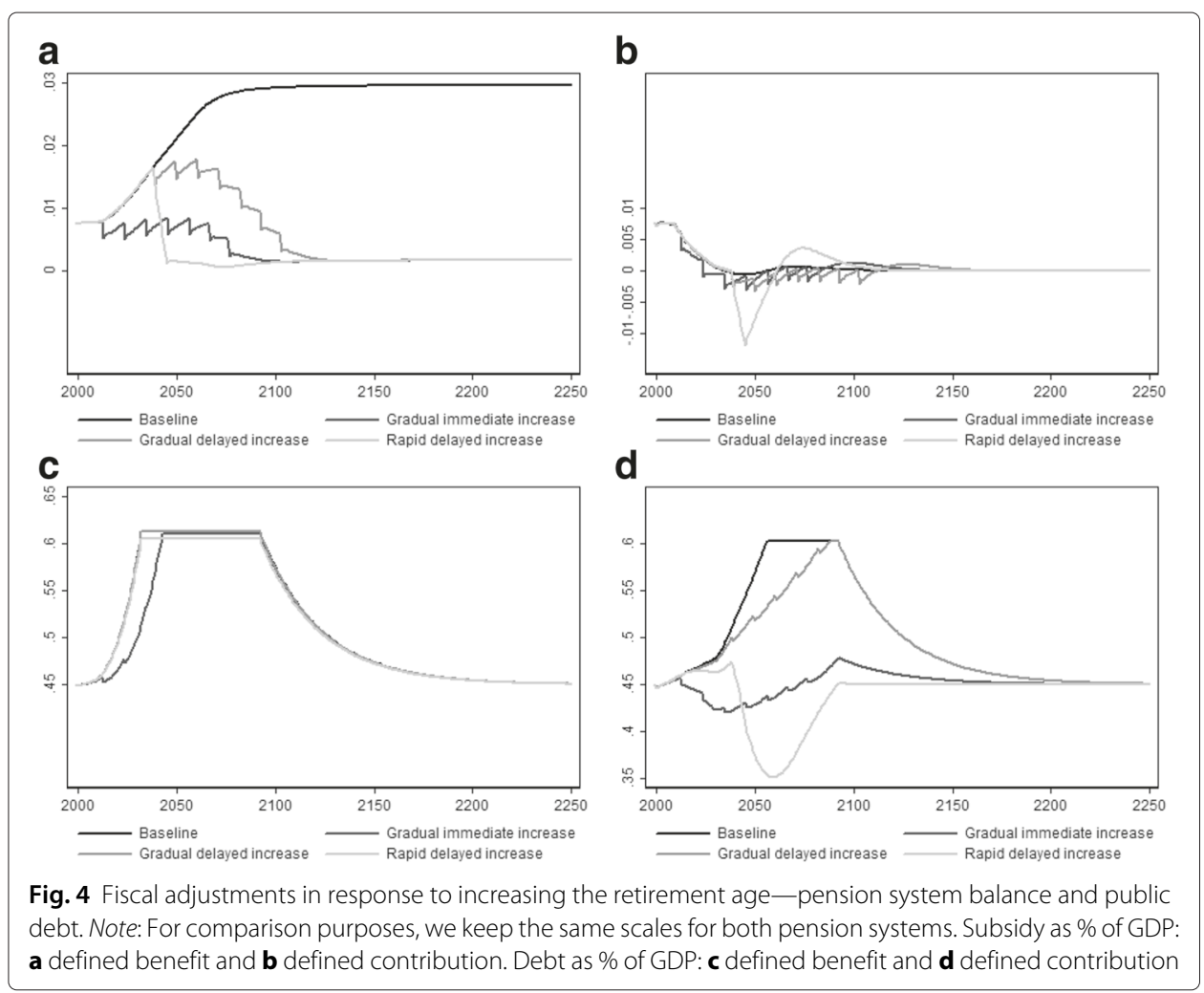

changes in the contribution base). In general, these systems are individually balanced, although temporary deficits or surpluses are possible due to swings in the dependency ratio. The opposite is true for benefits, i.e., DB system should see negligible changes in the level of pensions from the increase in the retirement age but substantial improvement in the pension system balance. In fact, the increase in the retirement age effectively balances the pension system in the case of the DB system (see Fig. 4c). There is also an additional channel of effects on pension benefit receipts, i.e., a shorter retirement period lowers the total discounted pension payments per retiree. Conversely, in the DC system, the main effect on incomes and consumption comes from higher per capita pension benefit receipts (see Fig. 3c, d). In fact, in the DC system, raising the retirement age yields a sort of double gain to the retirees. Namely, a longer contributory period makes the amount of savings on individual accounts larger, which results in higher discounted pension payments per retiree. An additional effect comes from a shorter retirement period, so higher accumulated pension savings are paid over lower number of years. Thus, the level of pensions raises even more than the discounted pension payments (Fig. 3d).

An interesting effect of longevity surfaces in both pension systems, although relatively stronger in the transition to DC. Namely, agents become effectively more patient thanks to longevity, so savings are relatively higher and consumption is relatively lower, thus reducing the consumption tax base. This diminution in consumption tax revenue is not compensated by the increase in capital income tax revenue, which triggers a fiscal adjustment in the only free fiscal parameter in our model, i.e., initially the public debt and subsequently the consumption tax. Consequently, the final steady state has a higher level 
of consumption taxes, while even an economy with a fiscally neutral pension systemsuch as DC-experiences an increase in public debt until threshold and subsequent surge in the consumption tax. A parametric reform of increasing the retirement age mitigates these effects. There are two main channels: earned income (longer working period implies higher lifetime earnings) and labor supply (higher tax base for labor tax revenues). Additionally, in the case of the DB system, the pension system deficit is substantially lowered with the increase in the retirement age.

While overall increasing the retirement age seems to be net welfare enhancing, as we demonstrated in Table 1, the time patterns displayed in Fig. 3 already reveal that the distribution across cohorts will be diversified. One should expect all the future cohorts to gain from the analyzed reform, regardless of the pension system, but in the process of transition, there is a variety of pension benefit and tax adjustments which damage welfare for a number of cohorts. We show the number of the losing cohorts and the average loss in Table 1, whereas in Fig. 5 we analyze in detail the cohort distribution of welfare effects. For each of the analyzed scenarios, we present a path of the welfare gains for the respective cohorts, with the horizontal axis corresponding to the birth date of a cohort.

The nearly universal welfare gain from the increased retirement age differentiates somewhat our results from Auerbach et al. (1989), who find large welfare losses for the initial cohorts. However, Auerbach et al. (1989) employ reductions in the contribution rate as a fiscal closure, which yields no gains for the initial retirees and only minor gains for individuals close to retirement at the moment of the reform. ${ }^{16}$ In our setting, the lessened fiscal pressure allows for the consumption tax to be lower than in the baseline scenario, which redistributes welfare gains across all living cohorts. In fact, the average loss among the losing cohorts typically falls short of $0.5 \%$ of lifetime consumption and is substantially reduced-both in size and in scope-if the increase in the retirement age is delayed. While it appears that the gain from lower taxes is higher-in terms of welfare-than the loss due to forced longer labor market activity, we emphasize that the effects are similar in size and scope for both the DB system and the transition to DC system. The differences in the welfare effects depending on the type of retirement age reform (immediate vs. delayed and rapid vs. gradual) are indeed similar.

While the effects are similar, as we discussed above, they are mediated by different channels. These different channels are likely to have dissimilar effects between agents who have some room to adjust savings or labor supply and those who do not, as argued earlier
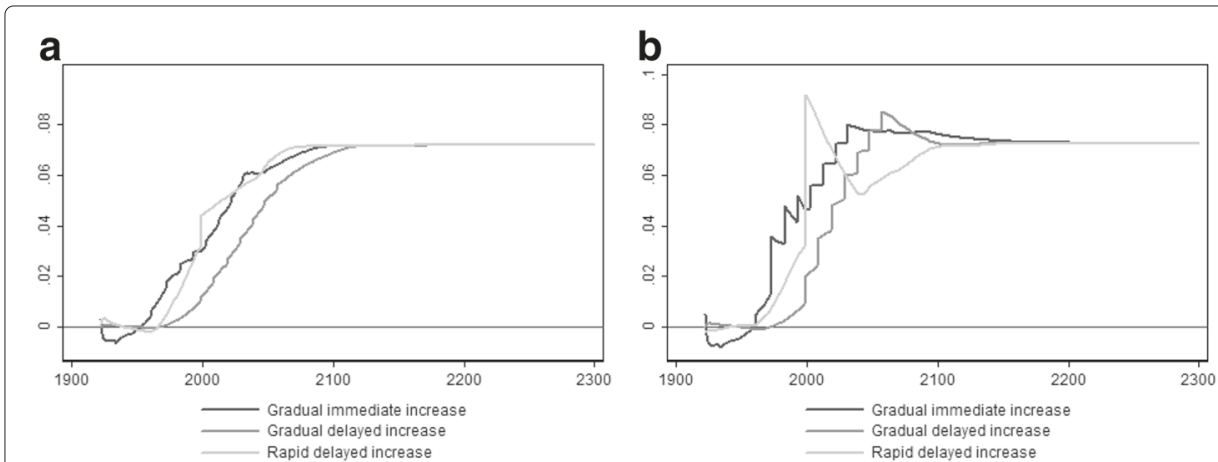

Fig. 5 Welfare effects from extending the retirement age-in \% of consumption equivalents. a Defined benefit. b Defined contribution 
by Hairault and Langot (2008) and Song (2011). We address this point in the next section where we analyze welfare effects for within-cohort heterogeneity.

\section{Within-cohort heterogeneity-welfare analysis}

With heterogeneous agents within a cohort, for each cohort, we obtain a distribution of welfare effects. We present the extreme values of this distribution-minimum and maximum-as well as the positional measures of the consumption equivalents for the analyzed reform scenarios in Fig. 6 . In all of the figures, the black line corresponds to the median agent, which should roughly correspond to the results of the representative agent economy discussed in Section 5. The distribution of the welfare effects is indeed wide, ranging from virtually 0 welfare gain to as much as $20 \%$. Yet, the sign of the welfare effects is universally preserved for the future cohorts and is only slightly differentiated. More importantly, the complementarity of the systemic and parametric reforms holds even in the setting of within-cohort heterogeneity. Namely, for each of the reform scenario,

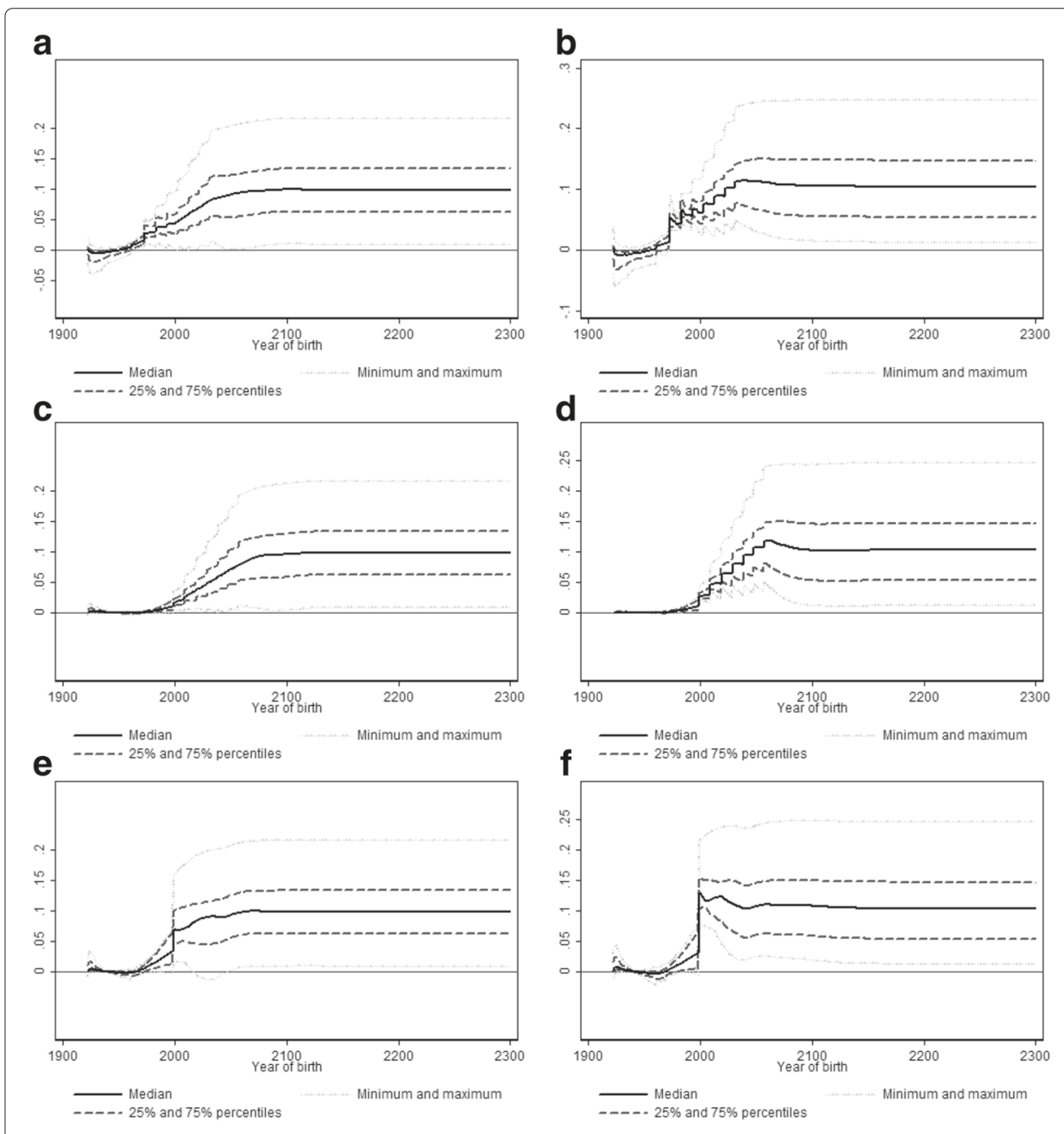

Fig. 6 Welfare effects as consumption equivalents—distribution over all subcohorts. Gradual and immediate increase: $\mathbf{a}$ DB and $\mathbf{b}$ DC. Gradual delayed increase: $\mathbf{c}$ DB and $\mathbf{d}$ DC. Rapid delayed increase: $\mathbf{e} D B$ and $\mathbf{f} D C$ 
when the DB system is compared to the transition to the DC system, similar patterns are revealed across subcohorts.

While the positional measures of the distribution are interesting, it is not intuitive which subcohorts underlie the respective percentiles. Thus, we also include a similar analysis for some selected types of subcohorts ${ }^{17}$ in Figs. 8 and 9 in Appendix 4. As expected, the variation in productivity endowment $\omega$ does not imply heterogeneity in welfare effects. Yet, differences in preference parameters drive substantial dispersion in the observed welfare effects. In fact, the minimum welfare group from Fig. 6 consists mostly of individuals with high preference for leisure and high impatience, while the opposite holds for the maximum welfare group. Acknowledging these differentiations, two main conclusions emerge. First, the sign of the median agent is preserved even for the extreme combinations of the preference parameters, which implies that the earlier conclusion is not a result of a fairly ad hoc definition of the instantaneous minimum or maximum but a feature of the reform. Second, the paths of welfare effects are strikingly similar across the pension systems. These results show that the welfare effects of increasing the retirement age are indeed universal, i.e., agents with low patience, high preference for leisure, and low productivity endowment have the same sign of the welfare effect as the representative agent. However, as in the case of Fig. 6, this holds for the delayed and gradual reforms. ${ }^{18}$

An increase in the retirement age postpones the period in which households start to receive pension benefits, which has two effects. First, additional cohorts stay in the labor market, which raises labor supply sharply. Second, cohorts having sufficient number of working periods prior to the retirement age are able to adjust labor supply to optimal levels by changing the hours worked. Agents forced to stay longer in the labor market may increase the hours of leisure in every period in order to achieve a higher overall utility (see Boersch-Supan and Ludwig 2010). We decompose the change in labor supply to intensive and extensive margins. In aggregate terms, the downward adjustment in labor supplied before the age of 60 is more than compensated by the additional years of working due to the increased retirement age. In our setting, in the original steady state, labor supply amounts to $55.3 \%$ of their available time. Demographic transition alone increases this indicator to $61.7-63.2 \%$ in the final steady state (depending on the pension system). Overall, increasing the retirement age by 7 years implies an increase in workable time by $17.5 \%$ (in the initial steady state, agents work for 40 years). The average increase in the overall supply of labor falls into the range between 13.7 and $15.4 \%$, depending on the analyzed scenario. However, these effects are not independent of the preferences. ${ }^{19}$ The results for the subcohorts are displayed in Table 2, whereas in Appendix 4: Figs. 10 and 11, we show the lifetime patters on labor supply under DB and DC, respectively.

Table 2 Labor supply adjustment for heterogeneous agents—final steady state

\begin{tabular}{|c|c|c|c|c|c|c|c|c|c|}
\hline \multirow{2}{*}{\multicolumn{2}{|c|}{$\begin{array}{l}\text { Pension system } \\
\text { Overall adjustment } \\
\text { in labor supply }\end{array}$}} & \multicolumn{4}{|c|}{$\begin{array}{l}\text { Defined benefit } \\
\phi \text { multiplier }\end{array}$} & \multicolumn{4}{|c|}{$\begin{array}{l}\text { Defined contribution } \\
\qquad \phi \text { multiplier }\end{array}$} \\
\hline & & \multirow{2}{*}{$\begin{array}{l}0.5(\%) \\
123\end{array}$} & \multirow{2}{*}{$\begin{array}{l}1(\%) \\
119\end{array}$} & \multirow{2}{*}{$\begin{array}{l}1.5(\%) \\
117\end{array}$} & \multirow{2}{*}{$\frac{2(\%)}{117}$} & \multirow{2}{*}{$\begin{array}{l}0.5(\%) \\
119\end{array}$} & \multirow{2}{*}{$\begin{array}{l}1(\%) \\
117\end{array}$} & \multirow{2}{*}{$\begin{array}{l}1.5(\%) \\
117\end{array}$} & \multirow{2}{*}{$\frac{2(\%)}{117}$} \\
\hline$\delta$ multiplier & 0.98 & & & & & & & & \\
\hline & 1 & 112 & 113 & 115 & 117 & 109 & 112 & 115 & 117 \\
\hline & 1.02 & 100 & 108 & 113 & 117 & 97 & 107 & 113 & 117 \\
\hline
\end{tabular}

The fully inelastic adjustment, without any behavioral response, implies increase in labor supply by $17.5 \%$. For brevity, we omit $\omega$, since it had negligible and only level effect on labor supply; detailed results available upon request 
Clearly, even if during the lifetime there is a downward adjustment in the labor supply, overall, the risks suggested by Boersch-Supan and Ludwig (2010) materialize only to a small extent in our model-labor supply increases substantially and for nearly all types of subcohorts (the only exception are agents with high impatience and high preference for leisure, especially in the DC system). Moreover, the ranking of adjustments in the labor supply is preserved across the pension systems for the respective subcohorts. The increases are similar across the pension systems, although DC provides stronger incentives for work. The higher the preference for leisure and impatience, the larger the scope of labor supply adjustment.

The comparison in Appendix 4: Figs. 10 and 11 reveals, as well, that while our utility function makes labor supply decision fairly resilient to the changes in the incentives, introducing the heterogeneity in terms of preference parameters allows to explore a wide variety of lifetime patterns of the labor supply. Given this differentiation, the result of universal welfare gains should be more convincing.

As a final step, we explore the within-cohort heterogeneity to provide some insights for the political economy. We also find that the welfare effects are universal across subcohorts, i.e., even the extremes of the welfare distribution preserve the sign from the representative agent. Yet, during the transition, the pattern of welfare effects depends on the phasing in of the retirement age reform. Thus, we can obtain the percentage of the living cohorts that benefit from the parametric reform for both DB and transition to DC at each point in time. The results are displayed in Fig. 7.

Intuitively, with the time passing by, the support for the reform implemented in $t=1$ will gradually increase, since future cohorts benefit from the reform. It is an empirical matter, however, if there is enough support for such a reform in $t=1$, i.e., can it be politically viable and is political viability different under the DB pension system than that under the DC pension system. In the case of our model, with heterogeneous agents within cohorts and 80 overlapping cohorts, the share of agents who experience a welfare gain is never short of $50 \%$, which would suggest this reform is actually politically viable for rational agents. A relatively lower support for delayed reforms stems from the fact that initially living cohorts observe no welfare effects but the support for this type of reform increases steeply with the arrival of new cohorts in subsequent years. Clearly, since welfare costs are concentrated among fewer cohorts in the case of DB than in the case of the DC pension system, the initial support is larger in the former.

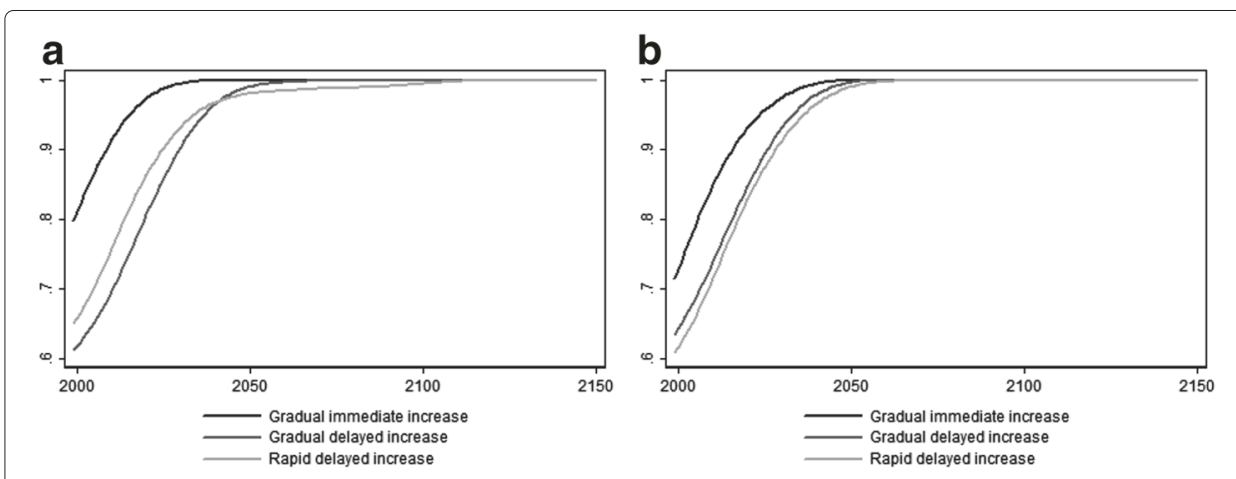

Fig. 7 Percentage of population benefiting from the reform. a Defined benefit. b Defined contribution 
Nowhere in this paper do we demonstrate-nor argue-that either of the two pension systems themselves are welfare enhancing. It is possible that in the absence of a universal pension system as well as retirement age, agents would alternatively choose consumption, labor, and savings, working possibly less over possibly a longer share of their lifetime. In fact, there should be no gains from increasing the retirement age, as there should be no gains from a pension system at all, as long as agents are unconstrained in consumption/savings choices and can work as long as they like. Thus, rather than actual gains from retirement age increase, the results demonstrate reduction in welfare distortions introduced in baseline specification. However, such property of the model is only preserved if there is no age-dependent morbidity ${ }^{20}$ or if there is no aggregate oversaving in the economy. These assumptions are violated in our cases-there is age-dependent non-zero probability of death at any given age $j$. Moreover, the baseline DC economy oversaves. In Appendix 5: Fig. 16a-d, we show graphically that in the final steady state the baseline allocation under the DC system could be improved with labor adjustment at extensive margin and/or reduced saving.

Summarizing, the welfare effects of increasing the retirement age are similar for an economy with a DB pension system and for an economy in transition to a DC system. This result is robust to various rates of phasing in the parametric reform. We also find that under plausible calibration, welfare effects are generally positive for all cohorts, provided that agents have sufficient time to adjust labor supply and savings to the changing conditions. Thus, delayed reforms seem to be preferable to immediate ones. Whether or not the reform is gradual does not affect the overall welfare substantially but may cause the losing cohorts (and subcohorts) to experience a lower decrease in consumption equivalents.

These conclusions prove to be universal for agents with heterogeneous preferences and endowments. Introducing heterogeneity allows to elaborate further on the point raised by Hairault and Langot (2008) that for some types of agents there may be insufficient room to adjust savings and labor supply, thus leading to welfare deterioration for these groups of agents via the general equilibrium effects. We show in detail the adjustment in labor supply, consumption, and savings and find virtually no corner solutions. Of course, by assuming the Cobb-Douglas shape of the utility function, we constrained the scope of adjustments in the overall lifetime labor supply. Yet, the instantaneous labor supply in a lifetime does adjust to the changing incentives. By introducing heterogeneous preferences, we are able to capture the differentiated adjustments in the labor supply for the respective combinations of preference for leisure and patience. Indeed, we find that for some types of agents the change in the age-labor supply pattern is substantial but the general increase due to the extensive margin trumps any intensive margin adjustment for nearly all types of preferences.

In general, the earlier literature has found that increasing the retirement age is a relatively "painless" adjustment and yields fiscal relief comparable to other "painful" reforms, such as reducing the benefits or increasing the contribution rates (e.g., Auerbach et al. 1989; Boersch-Supan and Ludwig 2010; Hviding and Marette 1998). We show, additionally, that welfare effects after implementing the systemic reform from a DB to a DC system are similar to those under a DB system, although channels of welfare effects differ. Gains can be universal even if we account for within-cohort heterogeneity. Notwithstanding, there is a number of caveats for the current study that constitute fruitful avenues for further research. 
First, it is in the nature of the OLG models that agents are equipped with perfect foresight and thus adjust savings to expected longevity (and-possibly-low pensions). As our model shows, this channel of adjustment may be quantitatively relevant not only for the welfare but also for the fiscal effects. Yet, the empirical evidence so far suggests that while in the real world indeed individuals exhibit some response in savings to changing incentives in the pension systems, the effects are typically small (e.g., Aguila 2011; Feng et al. 2011; Hurd et al. 2012; Lachowska and Myck 2015). This necessitates modifying the mechanics in the OLG models, but the solutions such as myopia (see Andersen and Bhattacharya 2011; Cremer and Pestieau 2011; Docquier 2002) or time inconsistency (see Caliendo 2011; Findley and Caliendo 2012; Imrohoroglu et al. 2003) have not proven to bring the simulation results substantially closer to the empirical estimates.

Second, the retirement decision has so far been under-researched in the literature. Much effort has been put into analyzing the political economy of voting over a de iure retirement age in the OLG framework. Yet, the labor market exit decision and the eligibility for receiving pension benefits could be considered as two separate dimensions of agents' optimization problem (Van Solinge and Henkens 2010). In our models, agents may decide to reduce the labor supply as early as preferable, but not after the minimum eligibility retirement age. Given these two main methodological limitations, as common as they are in the literature, the above results should be taken as an upper bound of the probable outcomes.

\section{Conclusions}

It is often argued that if a DB system is replaced with a DC system there is no need to raise the retirement age. In a sense, introducing a pension scheme which provides incentives to stay active longer in the labor market is believed to effectively address the problem of fiscal pressure due to increasing longevity. Yet, empirical evidence seems to suggest that even when incentives are aligned, the effective exit age falls short of the minimum eligibility retirement age (Heijdra and Romp 2009; Sauré and Zoabi 2012; Siegrist et al. 2007). The literature in the field typically falls into one of the two categories: a theoretical, stylized framework which answers a conceptual problem or a policy evaluation exercise which attempts to provide ex ante evaluation of potential reforms to the pension system. Our paper is closer to the latter strand, but it is distinguished by two contributions. First, we attempted to provide an intuition on whether the systemic reform is indeed substitutive to a parametric reform, as often argued in policy debate. Second, we sought to understand if the potential welfare effects are universal, taking into account differentiation across the birth cohorts and the within-cohort heterogeneity.

Our overlapping generation framework allows to compare two types of pension systems: defined contribution and defined benefit. We isolate the effects of longevity and account for the gradually decreasing rate of the technological progress. We nest in the model three types of retirement age reform which constitute the considered policy options: immediate gradual, delayed gradual, and delayed rapid. We supplement the standard overlapping generation model with a within-cohort heterogeneity. While some of the previous studies allowed for differences in endowments, our setting allows agents to differ in terms of time preference as well as leisure preference. 
Intuitively, increasing the retirement age may lower the labor supply of households at the intensive margin, thus reducing or even possibly eliminating the increase at the extensive margin. This type of adjustment was emphasized by Boersch-Supan and Ludwig (2010). In addition, Hairault and Langot (2008) argue that welfare effects can only be positive if agents can adjust both savings and labor supply "enough." For example, agents with low endowments and low labor supply (e.g., due to high preference for leisure) can only adjust at extensive margin, which is likely to substantially reduce their welfare.

In addition to the microeconomic adjustments, there are also macroeconomic consequences of increasing the retirement age. In a DB pension system, later retirement reduces fiscal imbalances, allowing welfare gains from lower taxes and/or public debt. Under DC schemes, there are no direct fiscal effects but pension benefits increase substantially. The objective of this paper was to compare the effects of delaying retirement in a DB pension system to the same parametric reform implemented in an economy which is already in transition to a DC pension system. For each of the systems, we simulate the economy with a status quo of unchanged retirement age and a variety of reform scenarios for increasing the effective retirement age. We compare welfare across cohorts and subcohorts to analyze the effects of such reforms.

Our study shows that even after a reform to a DC system, increasing the retirement age has the same welfare effects as under a DB system, although the channels of generating these welfare effects differ. We find that while differentiated preferences and endowments indeed imply dispersed welfare effects of the parametric reform, these results are similar in an economy with a DB system and in an economy in transition to a DC system. Moreover, if increasing the retirement age is implemented in a way that allows for smooth internalization of the changed incentives in the intertemporal and intra-temporal choices, the welfare gains from the reform are universal. While heterogeneous agents forced to work for more years adjust the average annual labor supply downwards, the aggregate labor supply is much higher in the reform scenario.

\section{Endnotes}

${ }^{1}$ Notwithstanding, the type of pension system may matter for the ability to internalize the consequences of longevity-the incentives towards early retirement in terms of pension benefit receipts seem stronger under DB than under DC schemes. Thus, empirical insights from the past-in general, mostly with DB systems-may be uninformative if systemic pension reform is in place, because DC improves the link between contributions (including the number of working years) and benefits. The majority of the empirical results comes from countries and times when changes in eligible retirement ages were rare, while the majority of systems had little or virtually no penalty in terms of future pension benefits and/or taxes for early exits.

${ }^{2}$ Also, empirical guidance on the actual exit behavior with a DC system and a high de iure retirement age is scarce.

${ }^{3}$ We extend a representative agent version of the model (see Goraus et al. 2014).

${ }^{4}$ See Hénin and Weitzenblum (2005); McGrattan and Prescott (2013) or Kindermann and Krueger (2014).

${ }^{5}$ We discuss the assumption of exogenous retirement age in Section 4.5.

${ }^{6}$ The model is calibrated to the case of Poland. Indexation is stipulated by legislation as the rate of the payroll growth.

${ }^{7}$ The details of this reform and modeling of the initial capital are similar to Makarski et al. (2016). 
${ }^{8}$ Depending on the period over which the average is taken, it ranges from $23.1 \%$ for 2 years before-after span and $24.1 \%$ for a 1 -year before-after span.

${ }^{9}$ Unlike McGrattan and Prescott (2013), we rely on individual rather than household data for three main reasons. First, we cannot obtain reliable indicators of individual productivity from household budget surveys, whereas family earned income is not recoverable in the labor force survey for the families where at least one family member has other-than-wage income. Second, both household budget survey data and the labor force survey data are self-reported, thus featuring all the well-known problems such as rounding the reported values of earnings and hours. Third, in the real economy, wage earners are employed in both the productive sector and the directly unproductive sector; the latter in our model is in fact expressed in terms of government consumption. For these three reasons we rely on the Structure of Earnings Survey. It covers the enterprise sector and comprises a sample approximately 20 times bigger than the LFS or HBS. The values of hours worked as well as earnings are reported in actual terms by the employers, which results in a substantially smoother distribution of the two variables. Finally, this way, we also avoid confusion of wage income and capital income (see McGrattan and Prescott 2013).

${ }^{10}$ We ran a similar analysis where median fitted value was to be the metric of endowments; the distribution is similar. The results are available upon request.

${ }^{11}$ For the wealth inequality, there is no empirical counterpart for Poland.

${ }^{12}$ See a special issue of Labor Economics (volume 22, 2013).

${ }^{13}$ In the alternative specification, we allow for the labor supply to be non-zero for $j \geq \bar{J}_{t}$ but reduce age-specific productivity $\omega_{j} \forall k$. We find that even if the productivity drops abruptly by $80 \%$ at $j=41$ (corresponding to the age of 60 in the data) the welfare of a representative agent is increased by the retirement age reform. Detailed calibration and results available upon request.

${ }^{14}$ In fact, we increase retirement age by 1 year for every consecutive cohort. If the increase in the retirement age was introduced at once, for 7 years, no cohort would retire, creating a substantial surplus in the pension system. Since the pension system balance affects budgetary balance, that would introduce unnecessary adjustments in the public debt and tax rates.

${ }^{15}$ Clearly, this statement does not imply that the gains are additive; the baseline scenarios differ for Makarski et al. (2016) and this study.

${ }^{16}$ In Auerbach et al. (1989), contribution rates balance the pension system, which implies that cohorts just prior to retirement have to work longer and see only a small gain in lowered $\tau$. Initially, young and future generations benefit from the positive effect on net wages. Retirees benefit only little from lower contribution rates and face disutility from reduced leisure, which implies a net negative welfare effect for the older cohorts.

${ }^{17}$ Full results for the 120 analyzed subcohorts available upon request.

${ }^{18}$ While the aggregate welfare effect of the representative agent economy ranges between 3.3 and $6 \%$, the overall welfare effect is stronger in the heterogeneous agents' economy, ranging between 4.6 and $8 \%$. This amplification is mostly due to the fact that the strongest losing subcohorts are those that have the lowest lifetime income and, thus, it is relatively less costly to compensate their losses.

${ }^{19}$ Admittedly, they are independent of endowments, as illustrated in Fig. 2i.

${ }^{20}$ In fact, if agents live with certitude until the last year and time preference equals the interest rate, pension systems are welfare deteriorating (absent liquidity constraints) and reforms to the retirement age may at best eliminate inefficiency. However, one can show in a model with liquidity constraints and longevity risk (we need neither in our exercise) that some pension systems are ex post welfare enhancing, since they provide insurance against outliving private savings. In the case of uncertain life duration, "non-Ricardian" effects appear, i.e., it matters for individual welfare in which period an agent receives income. 


\section{Appendixes}

\section{Appendix 1. Consumer problem solution}

For $j<\bar{J}$ :

$$
\begin{aligned}
c_{j, k, t} & =\frac{\left(1+\left(1-\tau_{t}^{k}\right) r_{t}\right) s_{j-1, k, t-1}+\left(1-\tau_{t}^{s}\right)\left(1-\tau_{t}^{l}\right) w_{t} \omega_{k}+\text { beq }_{j, t}+\Omega_{j, t}+\Gamma_{j, k, t}}{\left(1+\tau_{t}^{c}\right)\left[\sum_{s=0}^{\bar{J}-j-1}\left((1+\phi) \beta^{s} \frac{\pi_{j+s, t+s}}{\pi_{j, t}}\right)+\sum_{s=\bar{J}-j}^{J-j}\left(\beta^{s} \frac{\pi_{j+s, t+s}}{\pi_{j, t}}\right)\right]} \\
l_{j, k, t}= & 1-\frac{\phi\left(1+\tau_{t}^{c}\right) c_{j, k, t}}{\left(1-\tau_{t}^{s}\right)\left(1-\tau_{t}^{l}\right) w_{t} \omega_{k}} \\
s_{j, k, t} & =\left(1-\tau_{t}^{s}\right)\left(1-\tau_{t}^{l}\right) w_{t} \omega_{k} l_{j, k, t}+\left(1+\left(1-\tau_{t}^{k}\right) r_{t}\right) s_{j-1, k, t-1}-\left(1+\tau_{t}^{c}\right) c_{j, k, t},
\end{aligned}
$$

with

$$
\begin{aligned}
\Omega_{j, k, t} & =\sum_{s=1}^{\bar{J}-j-1} \frac{\left(1-\tau_{t+s}^{s}\right)\left(1-\tau_{t+s}^{l}\right) w_{t+s} \omega_{k} l_{j+s, k, t+s}+b e q_{j+s, t+s}}{\prod_{i=1}^{s}\left(1+\left(1-\tau_{t+i}^{k}\right) r_{t+i}\right)} \\
\Gamma_{j, k, t} & =\sum_{s=\bar{J}-j}^{J-j} \frac{\left(1-\tau_{t+s}^{l}\right) b_{j+s, k, t+s}^{l}+b e q_{j+s, t+s}}{\prod_{i=1}^{s}\left(1+\left(1-\tau_{t+i}^{k}\right) r_{t+i}\right)} .
\end{aligned}
$$

For $j \geq \bar{J}$ :

$$
\begin{aligned}
c_{j, k, t} & =\frac{\left(1+\left(1-\tau_{t}^{k}\right) r_{t}\right) s_{j-1, k, t-1}+\left(1-\tau_{t}^{l}\right) b_{j, k, t}^{l}+b e q_{j, t}+\Gamma_{j, t}}{\left(1+\tau_{t}^{c}\right)\left[\sum_{s=\bar{J}-j}^{J-j}\left(\beta^{\frac{s}{j+s, t+s}} \pi_{j, t}\right)\right]} \\
l_{j, k, t} & =0 \\
s_{j, k, t} & =\left(1-\tau_{t}^{l}\right) b_{j, k, t}^{l}+\left(1+\left(1-\tau_{t}^{k}\right) r_{t}\right) s_{j-1, k, t-1}-\left(1+\tau_{t}^{c}\right) c_{j, k, t},
\end{aligned}
$$

with

$$
\Gamma_{j, k, t}=\sum_{s=\bar{J}-j}^{J-j} \frac{\left(1-\tau_{t+s}^{l}\right) b_{j+s, k, t+s}^{\iota}+b e q_{j+s, t+s}}{\prod_{i=1}^{s}\left(1+\left(1-\tau_{t+i}^{k}\right) r_{t+i}\right)} .
$$

The numerators in Eqs. (8) and (9) represent the present discounted value of the remaining lifetime income.

\section{Appendix 2. Model solving}

This section describes the construction of the multi-agent model used to simulate the scenarios of pension system reform. We present all classes of agents in the system and the way they interact in the process of simulation. The multi-agent system created to simulate the effects of pension system reform consists of three different types of agents, representing various elements of the domain-government agent, private sector agent, and multiple subcohorts, i.e., heterogeneity within a single cohort.

Subcohorts They represent a part of a cohort that shares the same parametrization, that is, productivity $\omega$, preference for leisure $\phi$, and time preference $\delta$. In each year 
of the simulation, each subcohort either divides her time between labor and leisure given Eqs. (1) and (2) and receives salary from the private sector agent (if she is working) or receives benefits from the government agent (if she is retired), depending on the age of this cohort, following the budget constraint (3). In both cases, she pays taxes to the government and spends some of its resources on consumption. Every subcohort decides about intra-temporal division of time to work and leisure and intertemporal division of income into consumption and savings in order to maximize lifetime utility.

Simulation process The objective is to calculate the effects of different pension systems on welfare in a society populated by different birth cohorts, where within each cohort agents have heterogenous preferences and endowments. To achieve this objective, the system calculates two steady states, representing the initial and final year of the modeled period, and then computes the transition path between them. Since the general algorithm for computing both the steady state and transition path is very similar, we describe it just once, introducing necessary distinctions.

Finding the problem solution is an iterative process using the Gauss-Seidel method. In each iteration, the choices of agents are updated. The process stops when the difference between the capital from the new iteration is indiscernible from the previous iteration, i.e., smaller than a given parameter $\epsilon$. On a transition path, the optimization criterion relies on a sum of $\epsilon$ from each period. The parameter $\epsilon$ has been set to $10^{-9}$ in the steady states $\left(L_{\infty}<10^{-9}\right)$ and a sum over all $T$ set to $10^{-3}$ for a transition path $\left(L_{1}<10^{-3}\right)$.

Every iteration consists of the same major steps. The government, basing on capital calculated in the previous iteration (or initial capital in the first iteration) and parametrization of the model, computes tax rates. Given these rates and the structure of the pension system, the government also computes pension benefits for the retired cohorts. Given the amount of capital and labor, firms set interest rates and wages. Given the tax rates, interest rates, and wages (as well as received bequests), subcohorts choose labor supplied for each year of their life in the system, as well as consumption and savings. Given these choices, savings are aggregated to capital, to be compared with the capital from the previous iteration. If the two values satisfy the norm condition, the process finishes. Otherwise, a new iteration starts.

\section{Appendix 3. Calibration}

Table 3 Calibrated parameters

\begin{tabular}{lll}
\hline$\alpha$ & Capital share & 0.31 \\
$\tau_{l}$ & Labor tax & 0.11 \\
\hline$\phi$ & Preference for leisure & 0.5 \\
$\delta$ & Discounting rate & 0.99 \\
$d$ & Depreciation rate & 0.0515 \\
$\tau$ & Total soc. security contr. & 0.061 \\
$\rho$ & Replacement rate & 0.18 \\
& & resulting \\
& Labor force participation & 55.3 \\
$r(d k) / y$ & Investment rate & 24.3 \\
$r$ & Interest rate & 6.3 \\
\hline
\end{tabular}




\section{Appendix 4. Simulation results}
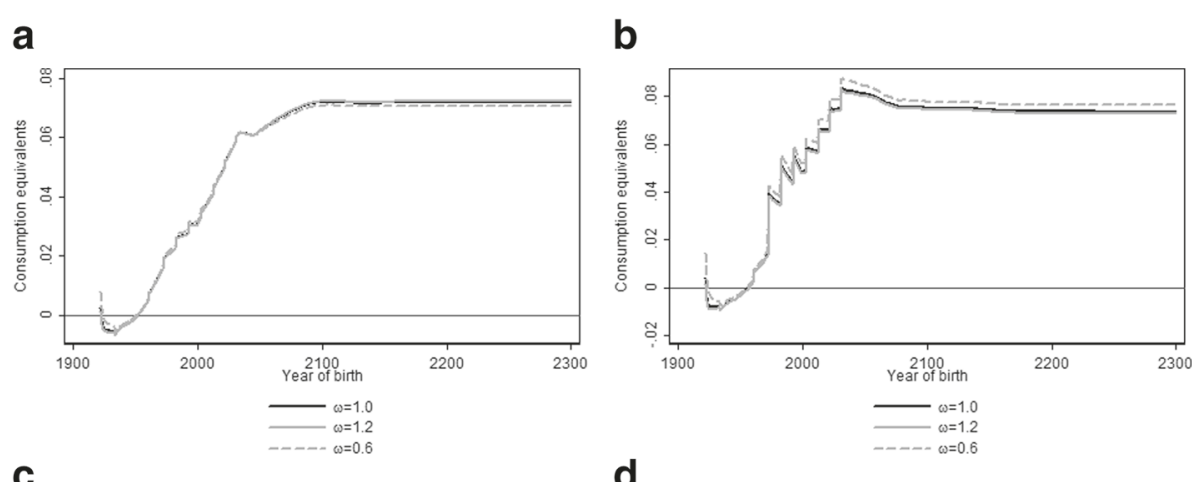

C

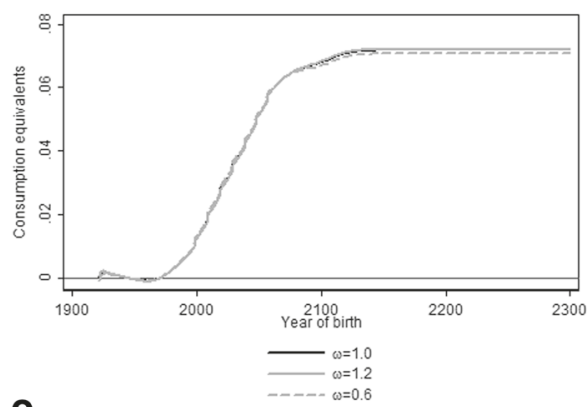

e
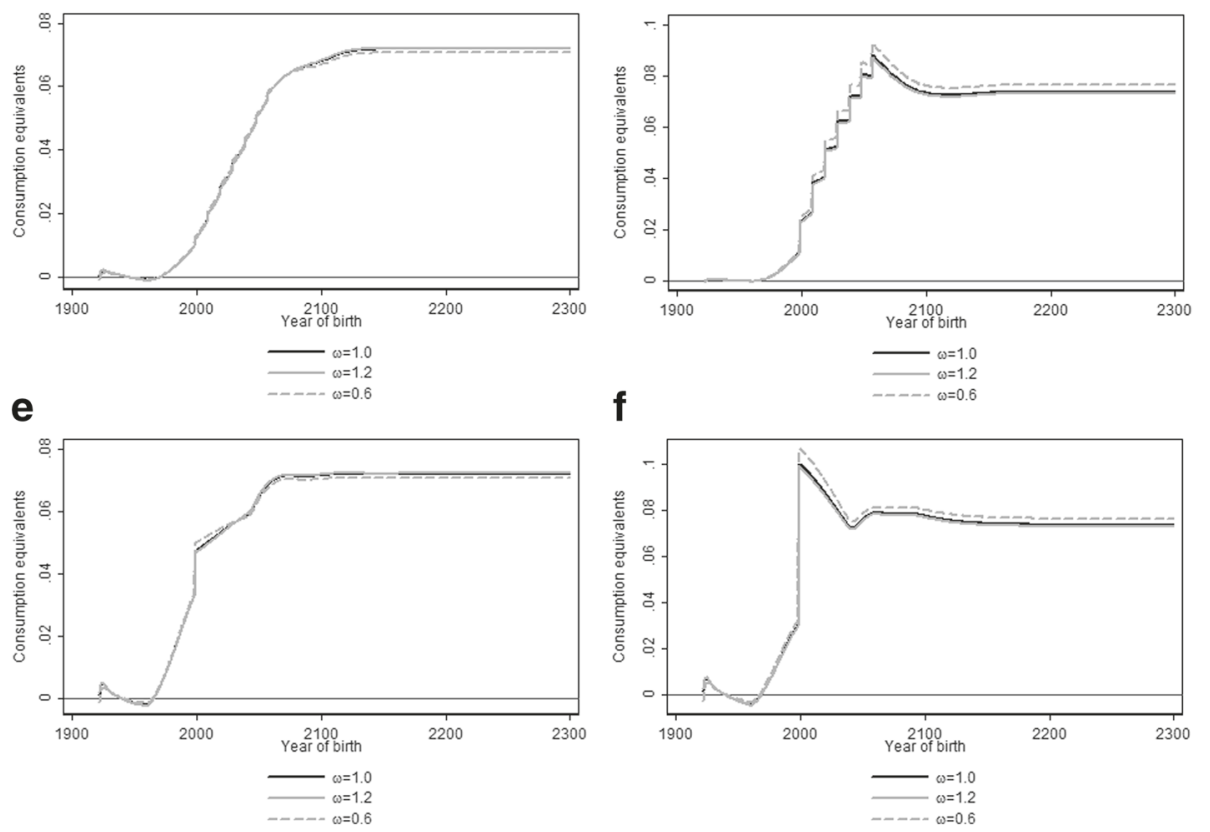

Fig. 8 Welfare effects (consumption equivalents) —subcohorts according to productivity. Note: In all the displayed simulation results, we keep $\delta=1$ and $\phi=1$. Gradual immediate increase: $\mathbf{a}$ DB and $\mathbf{b}$ DC. Gradual delayed increase: $\mathbf{c} D B$ and $\mathbf{d} D C$. Rapid delayed increase: e DB and $\mathbf{f} D C$ 

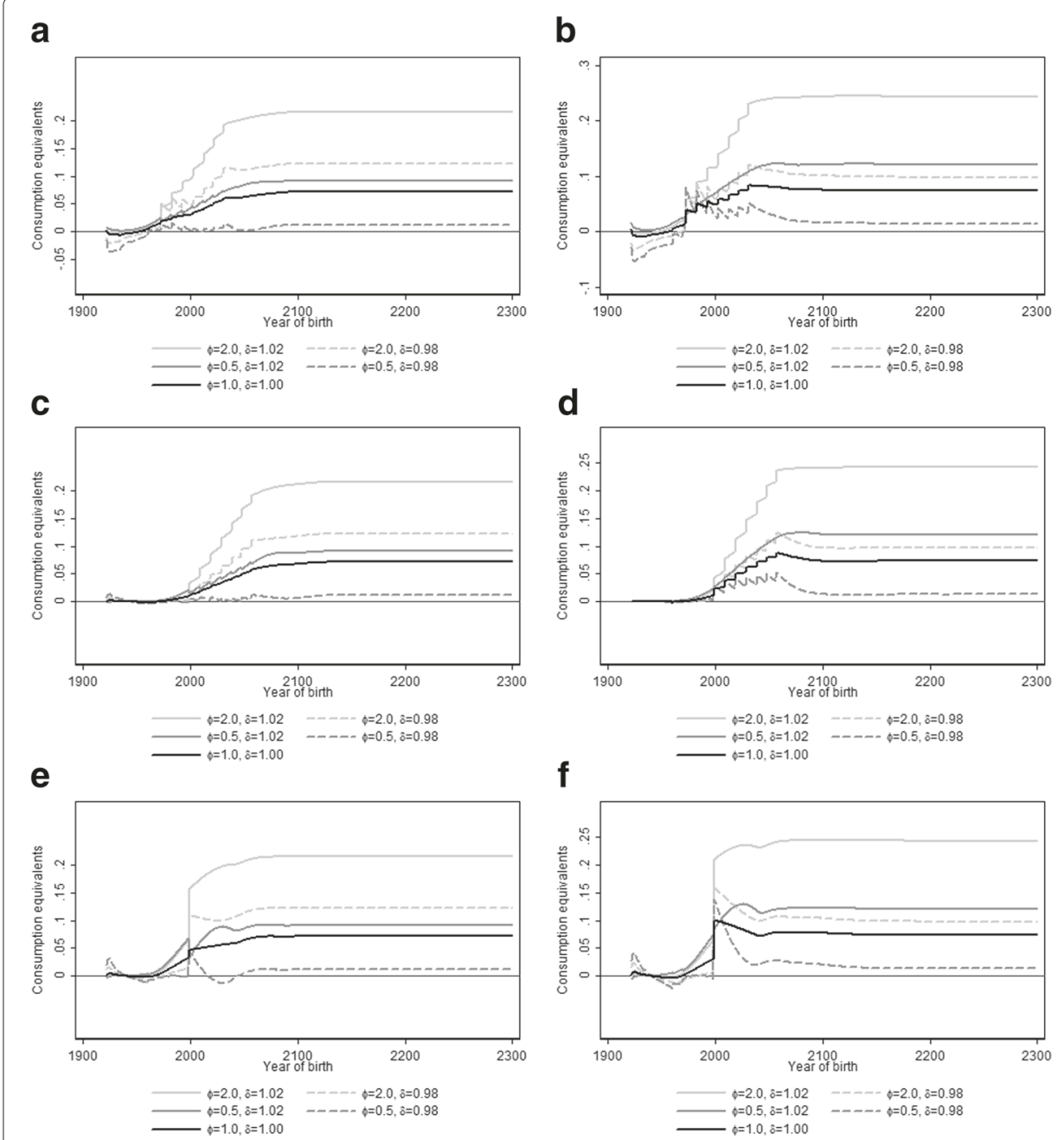

Fig. 9 Welfare effects (consumption equivalents)—subcohorts according to preferences. Note: In all the displayed simulation results, we keep $\omega=1$. Gradual immediate increase: a DB and $\mathbf{b}$ DC. Gradual delayed increase: $\mathbf{c}$ DB and $\mathbf{d}$ DC. Rapid delayed increase: $\mathbf{e} D B$ and $\mathbf{f D C}$ 


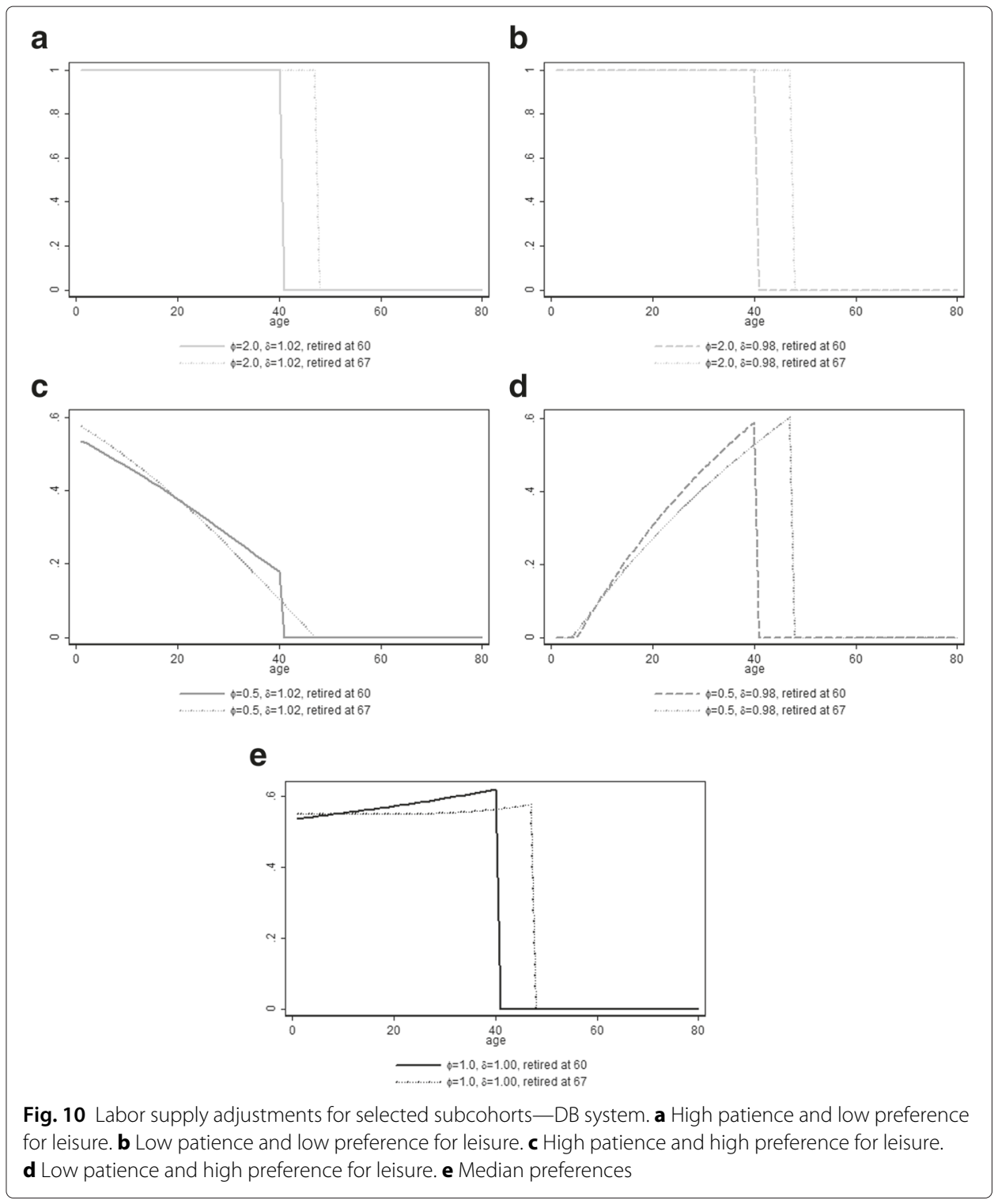




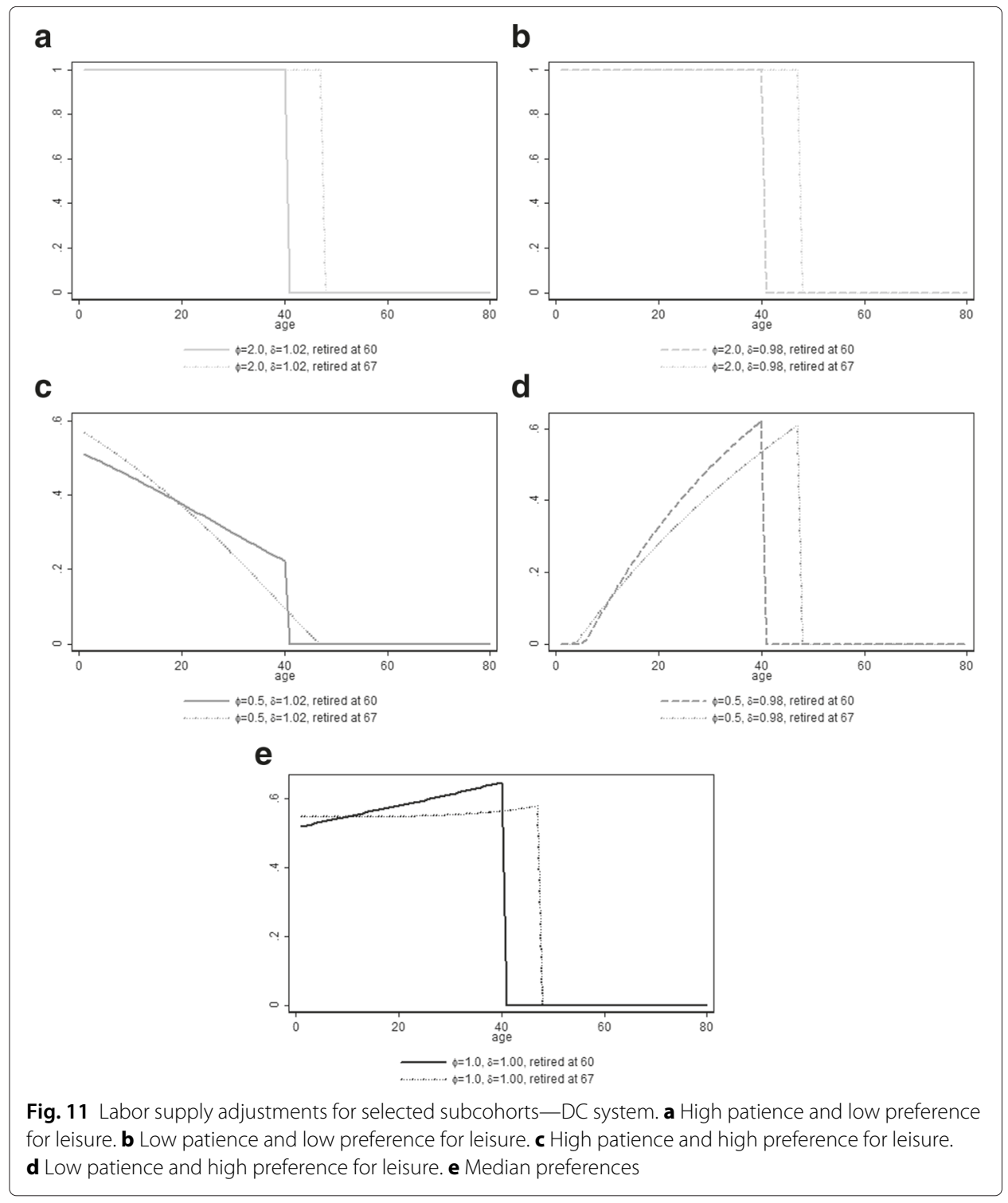



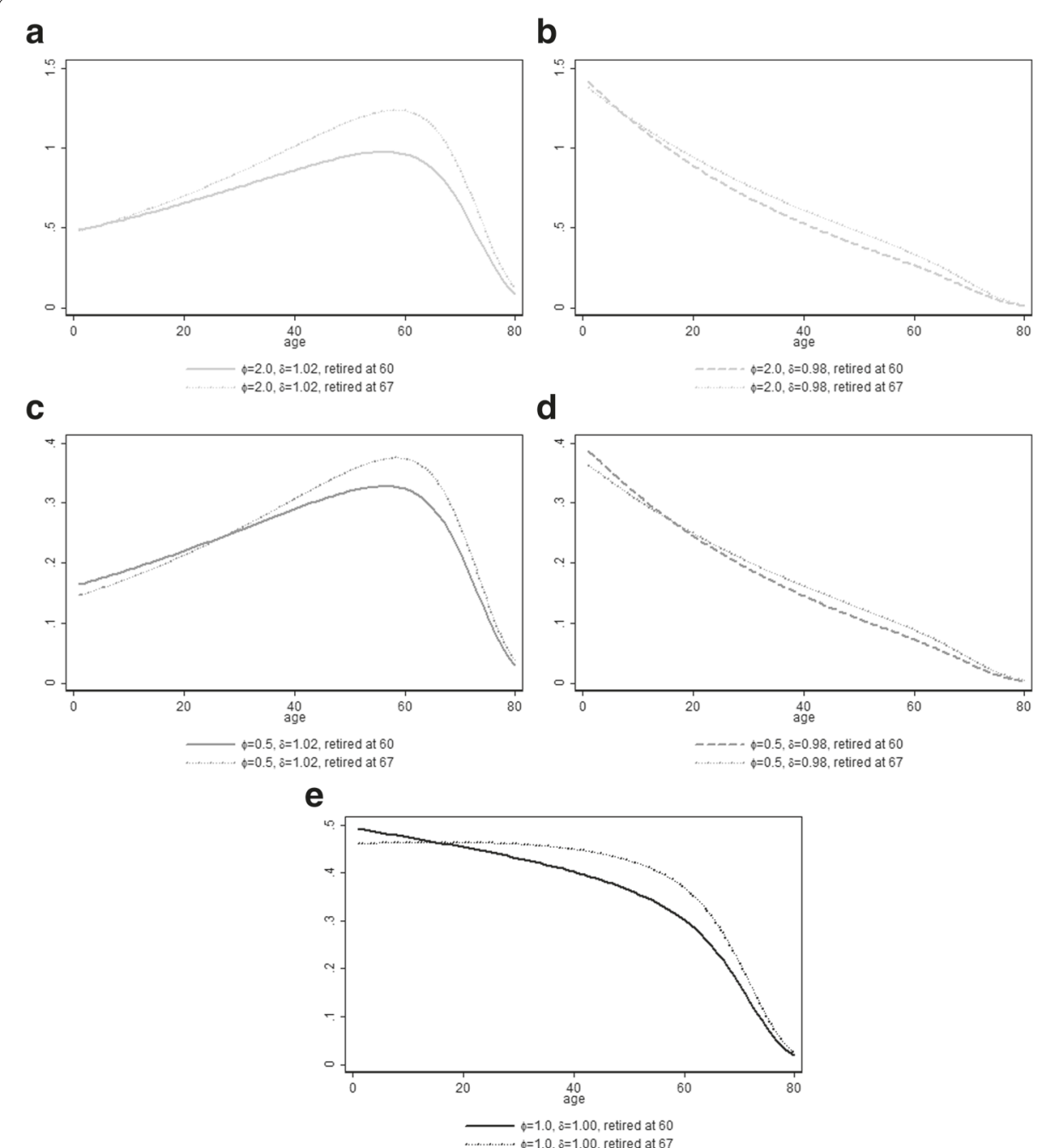

Fig. 12 Consumption adjustments for selected subcohorts-DB system. a High patience and low preference for leisure. b Low patience and low preference for leisure. $\mathbf{c}$ High patience and high preference for leisure. d Low patience and high preference for leisure. e Median preferences 


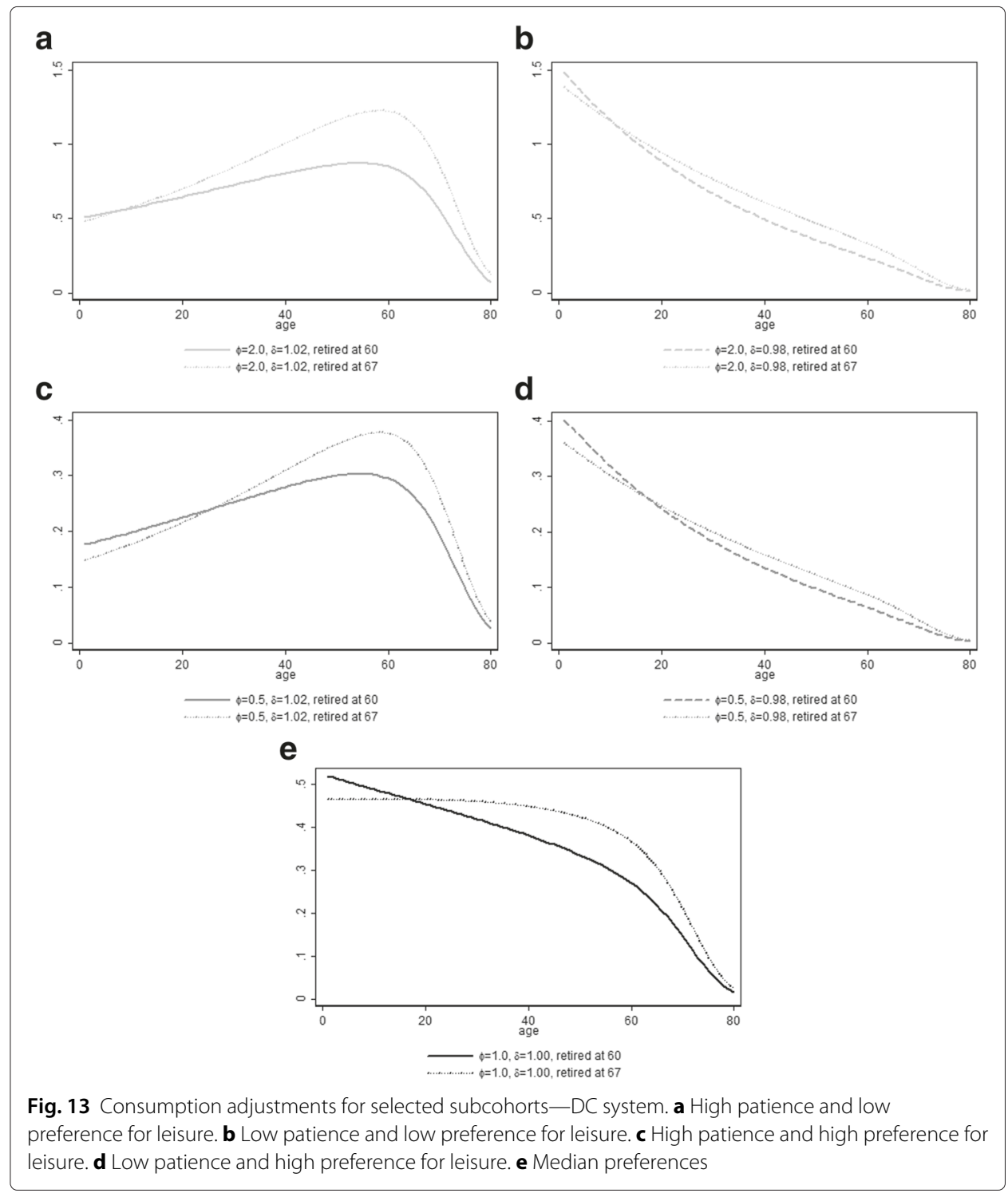


a

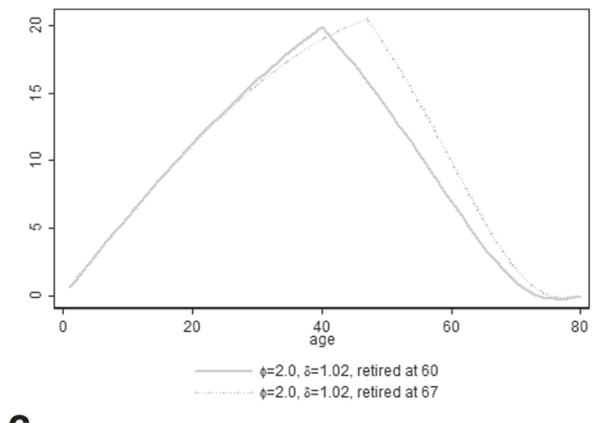

C

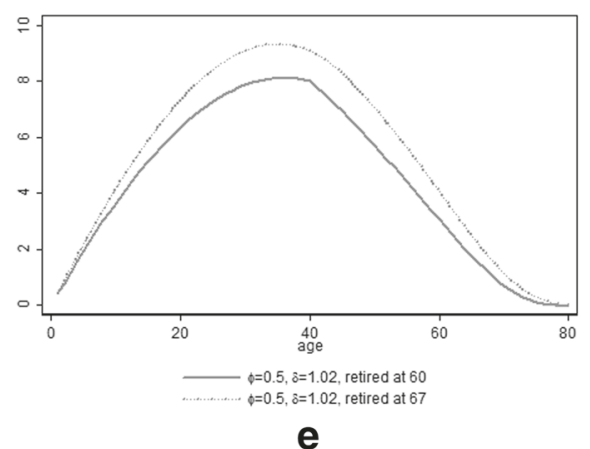

b

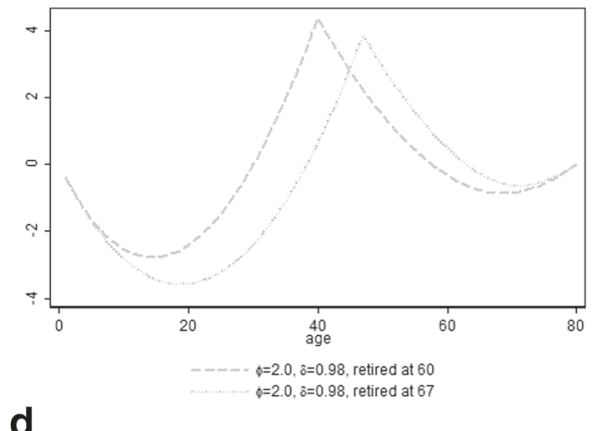

d

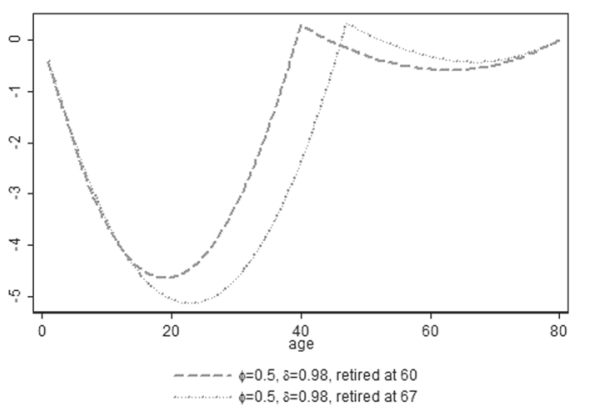

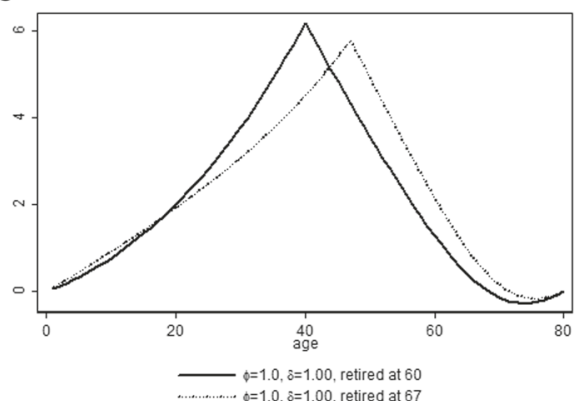

Fig. 14 Savings adjustments for selected subcohorts-DB system. a High patience and low preference for leisure. $\mathbf{b}$ Low patience and low preference for leisure. $\mathbf{c}$ High patience and high preference for leisure. $\mathbf{d}$ Low patience and high preference for leisure. e Median preferences 


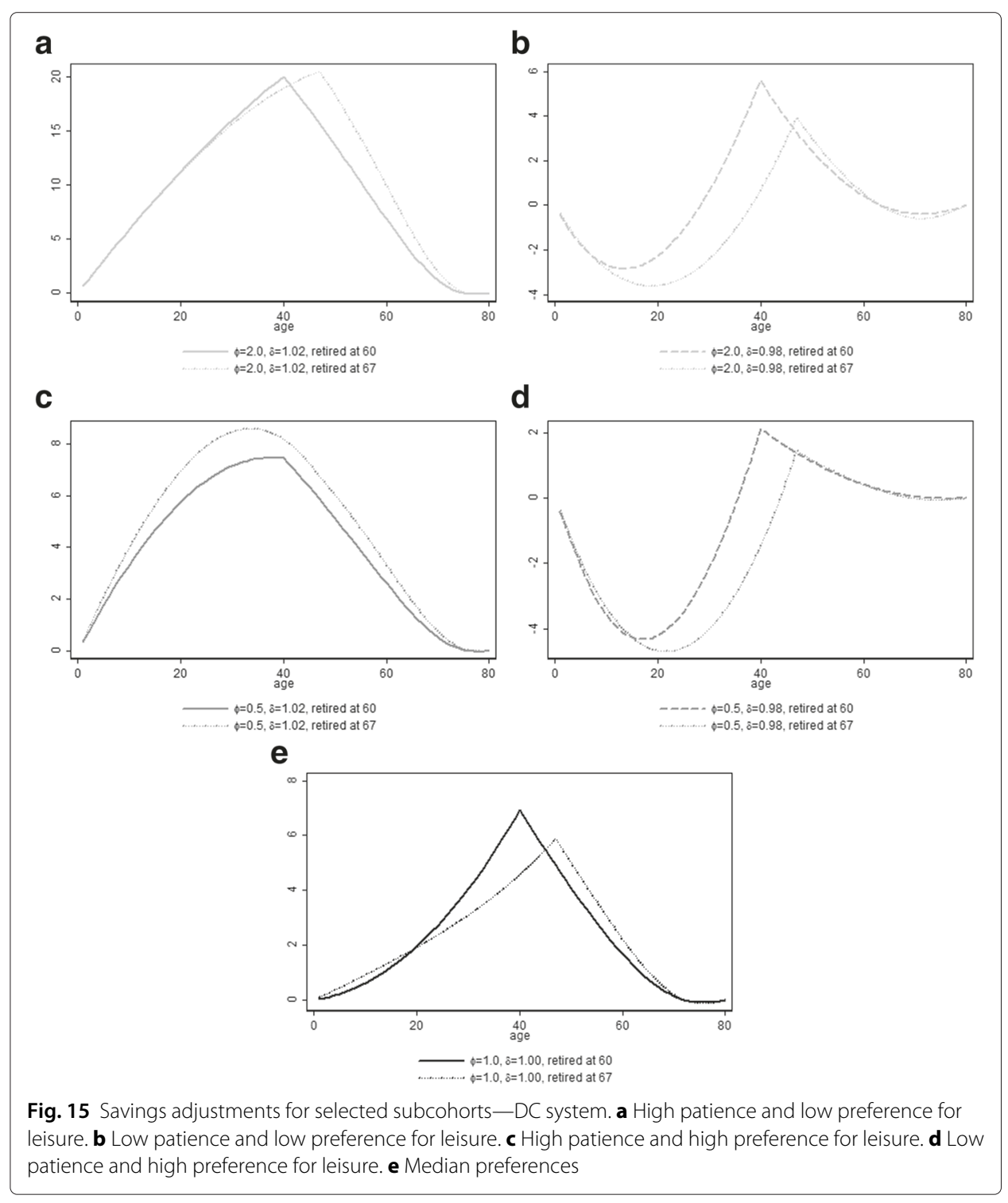




\section{Appendix 5. Oversaving}

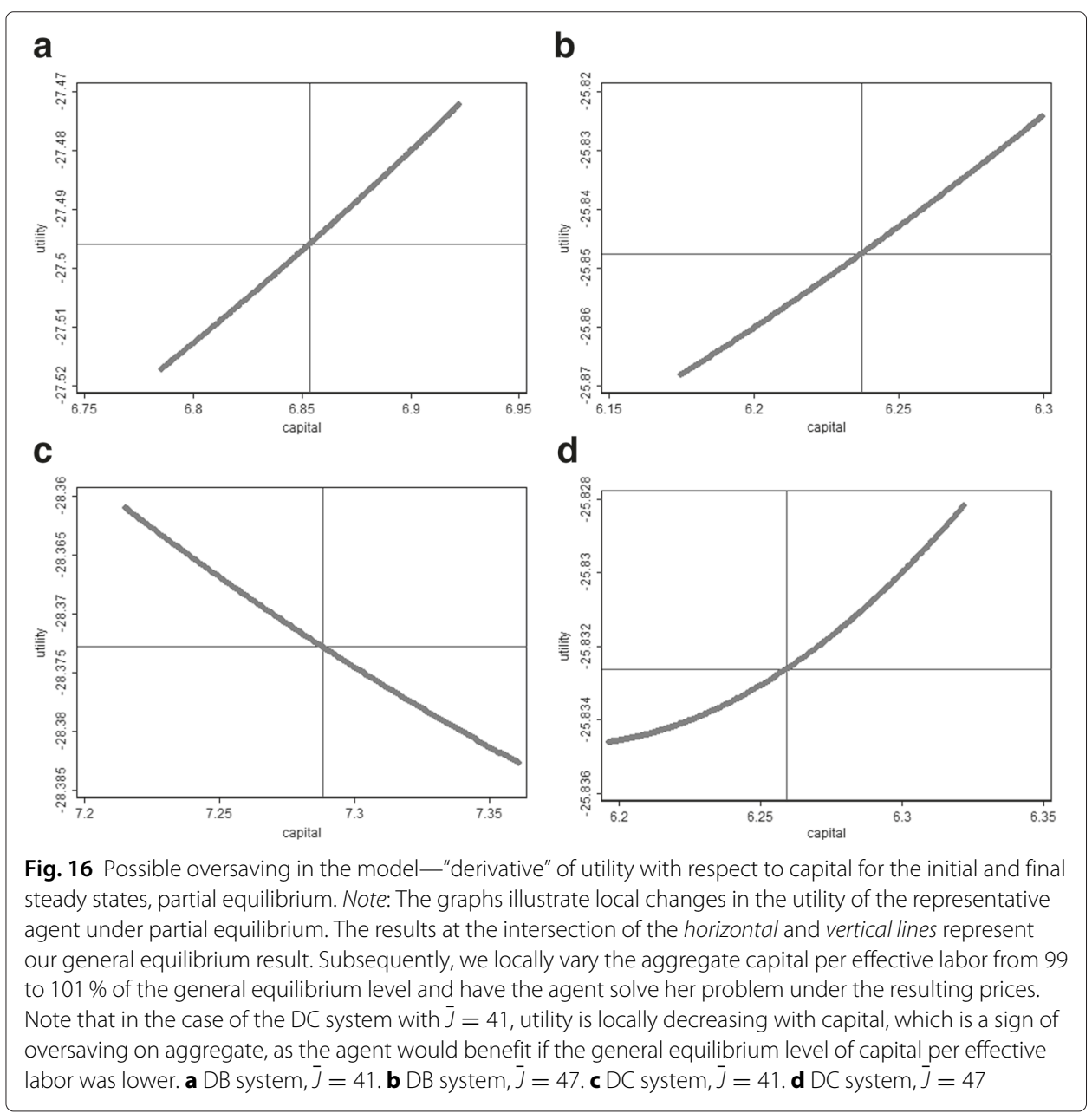

\section{Competing interests}

The IZA Journal of Labor Policy is committed to the IZA Guiding Principles of Research Integrity. The authors declare that they have observed these principles.

\section{Acknowledgements}

An earlier version of this paper has received extremely valuable comments from Fabian Kindermann, Patrick Puhani, Ayako Kondo, Dirk Niepelt, Hans Fehr, Martyna Kobus, Jan Hagemejer, Lukasz Drozd, Borys Grochulski, and Jaromir Nosal as well as participants of IZA/RIETI Workshop, SSES 2015, IPW 2015, EALE-SOLE 2015, GRAPE, NBP, and SGH seminars for insightful suggestions. Karolina Goraus and Marcin Waniek provided excellent research assistance. The paper has greatly benefited from the comments by an anonymous referee and editor. The remaining errors are ours.

The support of the National Science Centre (grant UMO-2012/01/D/HS4/04039) is gratefully acknowledged. All opinions expressed are those of the authors and have not been endorsed by NSC, nor NBP. An earlier version of this paper was presented on a workshop co-sponsored by IZA and RIETI.

Responsible editor: Juan Jimeno

\section{Author details}

${ }^{1}$ University of Warsaw, Warsaw, Poland. ${ }^{2}$ National Bank of Poland, Warsaw, Poland. ${ }^{3}$ Warsaw School of Economics, Warsaw, Poland.

Received: 23 July 2015 Accepted: 28 February 2016

Published online: 29 April 2016

\section{References}

Aguila E (2011) Personal retirement accounts and saving. Am Econ J: Econ Policy 3(4):1-24

Andersen TM, Bhattacharya J (2011) On myopia as rationale for social security. Econ Theory 47(1):135-158 
Auerbach AJ, Kotlikoff LJ, Hagemann RP, Nicoletti G (1989) The economic dynamics of an ageing population: the case of four OECD countries. OECD Economics Department Working Papers 62, OECD Publishing. doi:10.1787/054502801660 Beetsma RM, Bucciol A (2011) Differentiating indexation in Dutch pension funds. De Economist 159(3):323-360

Boersch-Supan A (2000) Incentive effects of social security on labor force participation: evidence in Germany and across Europe. J Publ Econ 78(1):25-49

Boersch-Supan A (2013) Ageing, labour markets and well-being. Empirica 40(3):397-407

Boersch-Supan A, Weiss M (2011) Productivity and age: evidence from work teams at the assembly line, MEA Discussion Papers 07148, Mannheim Research Institute for the Economics of Aging (MEA), University of Mannheim

Boersch-Supan A, Kohnz S, Schnabel R (2007) The budget impact of reduced early retirement incentives on the German public pension system. In: Social Security Programs and Retirement Around the World: Fiscal Implications of Reform. University of Chicago Press. pp 201-252

Boersch-Supan AH, Ludwig A (2010) Old Europe ages: reforms and reform backlashes. In: Shoven JB (ed). Demography and the Economy, NBER Books, National Bureau of Economic Research, In

Breyer F (1989) On the intergenerational Pareto efficiency of pay-as-you-go financed pension systems. J Institutional Theor Econ (JITE)/Zeitschrift für die gesamte Staatswissenschaft 145(4):643-658

Brzezinski M (2011) Accounting for recent trends in absolute poverty in Poland: a decomposition analysis. Post-Communist Econ 24(4):465-475

Bucciol A (2011) A note on social security welfare with self-control problems. Macroeconomic Dyn 15(04):579-594

Caliendo FN (2011) Time-inconsistent preferences and social security: revisited in continuous time. J Econ Dyn Control 35(5):668-675

Castaneda A, Díaz-Giménez J, Ríos-Rull JV (2003) Accounting for the US earnings and wealth inequality. J Pol Econ 111(4):818-857

Cremer H, Pestieau P (2003) The double dividend of postponing retirement. Int Tax Publ Finance 10(4):419-434

Cremer H, Pestieau P (2011) Myopia, redistribution and pensions. Eur Econ Rev 55(2):165-175

Deaton AS, Paxson CH (1998) Aging and inequality in income and health. American Economic Review:248-253

Díaz-Giménez J, Díaz-Saavedra J (2009) Delaying retirement in Spain. Rev Econ Dyn 12(1):147-167

Docquier F (2002) On the optimality of public pensions in an economy with life-cyclers and myopes. J Econ Behav Organ 47(1):121-140

Doepke M, Martin S, Selezneva V (2015) Distributional effects of monetary policy. In: 2015 Meeting Papers. 1099. Society for Economic Dynamics. https://www.economicdynamics.org/meetpapers/2015/paper_1099.pdf

Domeij D, Klein P (2002) Public pensions: to what extent do they account for Swedish wealth inequality? Rev Econ Dyn 5(3):503-534

Fehr H (2000) Pension reform during the demographic transition. Scand J Econ 102(3):419-443

Fehr $\mathrm{H}$ (2009) Computable stochastic equilibrium models and their use in pension- and ageing research. De Economist 157(4):359-416

Fehr H, Kindermann F (2010) Pension funding and individual accounts in economies with life-cyclers and myopes. CESifo Econ Stud 56(3):404-443

Fehr H, Uhde J (2014) Means-testing and economic efficiency in pension design. Econ Model 44:57-67

Fehr H, Habermann C, Kindermann F (2008) Social security with rational and hyperbolic consumers. Rev Econ Dyn 11(4):884-903

Fehr H, Kallweit M, Kindermann F (2012) Pension reform with variable retirement age: a simulation analysis for Germany. J Pension Econ Finance 11(03):389-417

Fehr H, Sterkeby WI, Thogersen O (2003) Social security reforms and early retirement. J Popul Econ 16(2):345-361

Feldstein M (1995) Would privatizing social security raise economic welfare? Working Paper Series 5281, National Bureau of Economic Research. http://www.nber.org/papers/w5281.pdf

Feng J, He L, Sato H (2011) Public pension and household saving: evidence from urban China. J Comp Econ 39(4):470-485

Fenge R, Pestieau P (2005) Social security and early retirement. The MIT Press, Cambridge

Findley S, Caliendo FN (2012) Time-inconsistency and retirement choice. Economics Letters 129(2015):4-8

Futagami K, Nakajima T (2001) Population aging and economic growth. J Macroeconomics 23(1):31-44

Galasso V (2008) Postponing retirement: the political effect of aging. J Publ Econ 92:2157-2169

Goraus K, Makarski K, Tyrowicz J (2014) Does social security reform reduce gains from increasing the retirement age?. Working Papers 2014-03, Faculty of Economic Sciences, University of Warsaw

Gruber J, Wise DA (2007) Social security programs and retirement around the world: fiscal implications of reform. NBER Books. National Bureau of Economic Research, Inc. http://www.nber.org/papers/w11290

Hairault JO, Langot F (2008) Inequality and social security reforms. J Econ Dyn Control 32(2):386-410

Heijdra BJ, Romp WE (2009) Retirement, pensions, and ageing. J Publ Econ 92:586-604

Hénin PY, Weitzenblum T (2005) Welfare effects of alternative pension reforms: assessing the transition costs for French socio-occupational groups. J Pension Econ Finance 4(03):249-271

Hurd M, Michaud PC, Rohwedder S (2012) The displacement effect of public pensions on the accumulation of financial assets. Fiscal Studies 33(1):107-128

Hviding K, Mérette M (1998) Macroeconomic effects of pension reforms in the context of ageing populations: overlapping generations model simulations for seven OECD countries. OECD Economics Department Working Paper 201. OECD Publishing. doi:10.1787/638376177076

Imrohoroglu A, Imrohoroglu S, Joines DH (2003) Time-inconsistent preferences and social security. Q J Econ 118(2):745-784

Jimeno JF, Rojas JA, Puente S (2008) Modelling the impact of aging on social security expenditures. Econ Model 25(2):201-224

Kindermann F, Krueger D (2014) High marginal tax rates on the top $1 \%$ ? Lessons from a life cycle model with idiosyncratic income risk. NBER Working Paper 20601. National Bureau of Economic Research, Inc. http://www.nber. org/papers/w20601

Kumru CS, Thanopoulos AC (2011) Social security reform with self-control preferences. J Publ Econ 95(7-8):886-899

Lachowska M, Myck M (2015) The effect of public pension wealth on saving and expenditure. IZA Discussion Paper 8895, Institute for the Study of Labor (IZA). http://ftp.iza.org/dp8895.pdf 
Lindbeck A, Persson M (2003) The gains from pension reform. J Econ Lit 41(1):74-112

Makarski K, Hagemejer J, Tyrowicz J (2016) Efficiency of the pension reform: the welfare effects of various fiscal closures. Macroeconomic Dynamics. forthcoming

McGrattan ER, Prescott EC (2013) On financing retirement with an aging population. NBER Working Paper 18760. National Bureau of Economic Research. http://www.nber.org/papers/w18760

Myck M (2010) Wages and ageing: is there evidence for the "Inverse-U Profile"? Oxf Bull Econ Stat 72(3):282-306

Nishiyama S, Smetters K (2007) Does social security privatization produce efficiency gains? Q J Econ 122:1677-1719

Sauré PU, Zoabi H (2012) Retirement age across countries: the role of occupations. Working Papers 2012-06

Schnalzenberger M, Schneeweis N, Winter-Ebmer R, Zweimüller M (2014) Job quality and employment of older people in Europe. Labour 28(2):141-162

Siegrist J, Wahrendorf M, Von dem Knesebeck O, Jürges H, Börsch-Supan A (2007) Quality of work, well-being, and intended early retirement of older employees: baseline results from the SHARE Study. Eur J Public Health 17(1):62-68

Song Z (2011) The dynamics of inequality and social security in general equilibrium. Rev Econ Dyn 14(4):613-635

St-Amant P-AB, Garon JD (2015) Optimal redistributive pensions and the cost of self-control. Int Tax Publ Finance:1-18. forthcoming

Storesletten K, Telmer Cl, Yaron A (2004) Consumption and risk sharing over the life cycle. J Monetary Econ 51 (3):609-633 Van Solinge H, Henkens K (2010) Living longer, working longer? The impact of subjective life expectancy on retirement intentions and behaviour. Eur J Publ Health 20(1):47-51

Vodopivec N (2010) Textile workers in Slovenia: from nimble fingers to tired bodies. Anthropol East Eur Rev 28(1):165-183

Wahrendorf M, Dragano N, Siegrist J (2012) Social position, work stress, and retirement intentions: a study with older employees from 11 European countries. European sociological review 29.4(2013):792-802

Wahrendorf M, von dem Knesebeck O, Siegrist J (2006) Social productivity and well-being of older people: baseline results from the SHARE study. Eur J Ageing 3(2):67-73

\section{Submit your manuscript to a SpringerOpen ${ }^{\odot}$ journal and benefit from:}

- Convenient online submission

- Rigorous peer review

- Immediate publication on acceptance

- Open access: articles freely available online

- High visibility within the field

- Retaining the copyright to your article

Submit your next manuscript at $\gg$ springeropen.com 